\title{
Static and Dynamic Gains from Costly Importing of Intermediate Inputs: Evidence from Colombia*
}

\author{
Hongsong Zhang, The University of Hong Kong
}

October 5, 2016

\begin{abstract}
This paper investigates the long-term effect of importing intermediate inputs on firm revenue and productivity, by estimating a dynamic model of firms' endogenous importing decisions with random sunk and fixed costs of importing. Based on counterfactual analysis, the model decomposes the gains from importing into a static revenue effect, resulting from improved quality and variety of available inputs, and a dynamic productivity effect, resulting from improved productivity. Empirical results from a Colombian plant-level dataset show that both the static and dynamic effects are important sources of gains from importing. It is also shown that the two types of trade liberalization, either by reducing the import tariff or by reducing sunk and fixed costs of import, both have a substantial impact on firm value.
\end{abstract}

Keywords: Import Intermediate Inputs, Productivity, Firm Value, Static Effect, Dynamic Effect

JEL classification: $F 14, F 2$

${ }^{*}$ The author is grateful to Mark Roberts, James Tybout, and Paul Grieco for many insightful comments. The author also would like to thank Jonathan Eaton, Donna B. Gilleskie, Kala Krishna, Edwin Lai, Amber Yao Li, Brian McManus, Albert Park, Klara Peter, Larry D. Qiu, Paul Scott, Valerie Smeets, Frederic Warzynski, Stephen Yeaple, Miaojie Yu, and Li'an Zhou, two anonymous referees, and the editor for their very constructive comments. The author also benefits from discussions with participants in the 2013 Econometrics Society North American Summer Meeting, 2013 European Association for Research in Industrial Economics (EARIE), and the IO reading group at the Pennsylvania State University. The author thanks Mark Roberts and James Tybout for providing the data used in the empirical application. All errors are the author's own responsibility.

${ }^{\dagger}$ Correspondence: 906 K.K.Leung Building, Faculty of Business and Economics, The University of Hong Kong, Hong Kong. Email: hszhang@hku.hk. Tel: (852)2859-2780. Fax: (852)2548-1152. 


\section{Introduction}

This paper examines the long-term effect of importing intermediate inputs on firm performance and quantitatively evaluate the relative importance of its effect through immediately increased revenue and dynamically increased productivity, by estimating a dynamic model of endogenous importing decisions at the firm level with random sunk and fixed costs of importing. The idea of this paper is motivated by two basic facts observed in a plant-level panel data from Colombia. First, firms that are importing intermediate inputs have much higher labor productivity than those not. Second, firms' labor productivity jumps up when they start importing and jumps down when they stop importing. Both of these two facts suggest labor productivity is positively correlated with importing behavior. This is consistent with existing literatures in international trade, which document a strong and positive correlation between productivity and importing. For example, using cross-country macro data, it is shown that countries more actively participating in importing have higher productivity levels and productivity growth rates (Coe and Helpman, 1995; Coe et al., 1997; Eaton and Kortum, 2002; Acharya and Keller, 2009) ${ }^{1}$. Keller (2004) has a review of the literature before 2004. Using recently available firm- or plant-level data it is shown that firm-level productivity are positively related to firms' importing behavior (Halpern et al., 2011; Bernard et al., 2009; Blalock and Veloso, 2007; Amiti and Konings, 2007; Kasahara and Rodrigue, 2008; Vogel and Wagner, 2010; Khandelwal and Topalova, 2011).

In general, there are three possible explanations to this observed positive correlation between importing and productivity. First, the productivity difference between importers and non-importers may be due to self selection of firms to import intermediate inputs. That is, more productive firms are more likely to import, as documented in Vogel and Wagner (2010). Second, importing may increase firm revenue immediately through increased quality and variety of available inputs, which improves firm performance, as documented in Kasahara and Rodrigue (2008), Goldberg et al. (2009, 2010), and Halpern et al. (2011). This revenue effect can increase the measured total factor productivity (TFP) of importing firms and it can happen even when the firm productivity/technology is not changed. We refer to this static revenue effect of importing as static effect throughout this paper. This static quality and variety effect is directly associated with the usage of imported inputs. Once a firm stops importing, it cannot benefit from it anymore. Third, importing experience may also have an impact on firms' productivity, which in turn influences firms' future importing decisions and productivity. I will call the effect from this productivityimporting interaction dynamic effect in this paper. This effect can arise from several different channels. For example, importing firms have more exposure to foreign knowledge and technology, which directly increase firms' knowhow about production. This change of knowledge can directly change firms' productivity in the future (e.g. to reduce shutdown of production line). Importing firms also usually receive some technical supports from their foreign suppliers, which directly changes their knowledge about production and will have a long-term impact in the future. Moreover, importing can also incur firms to invest more in $R \& D$ possibly due to the newly available

\footnotetext{
${ }^{1}$ Earlier studies such as Ethier (1982), Romer (1990), and Grossman and Helpman (1991) also find such a positive correlation.
} 
inputs and newly available knowledge from abroad which help the firm to reduce the cost of innovation and/or increase its chances of a successful R\&D. This increased R\&D investment due to importing can also increase firm productivity in the future. The term dynamic effect will contain all these productivity-importing interaction results, including the direct effect of importing on future productivity and the indirect effect of importing on future productivity through induced R\&D investment and other forms of investments. ${ }^{2}$ In either of the three cases, we would observe a positive correlation between importing and productivity. A key implication is that we need to estimate firms' endogenous importing decisions and account for both static revenue effect and dynamic productivity effect of importing simultaneously, in order to consistently evaluate the long-term and short-term effects of a change of importing policy, such as a reduction of importing barrier.

This paper estimates a dynamic structural model of firms' endogenous decisions on whether to import intermediate inputs or to rely exclusively on domestically-supplied inputs, and quantifies its static effect and dynamic effect on firm value separately. In the model, firm productivity evolves endogenously. The productivity, along with random fixed and sunk costs of importing and other factors, determines firms' importing decisions. The importing decisions, in turn, have a dynamic effect on the future productivity of the importing firms. The model provides an approach to estimating the short-term impact of importing on profit directly and simulating the long-term impact of import expansion on firm performance. Based on this dynamic structural model, as one contribution of this paper, we can use counterfactual analysis to separately quantify the static effect and dynamic effect of importing in terms of increased firm value, which is defined as the accumulated future profit. As specified in the model, the static effect, which results from improved quality and variety of intermediate inputs due to importing, increases current profit immediately. The dynamic effect, resulting from improved productivity due to importing, enhances future profitability. As part of the model I also estimate the dynamic policy function of plants' optimal importing decisions, which depends on expected future profits and current fixed or sunk costs of importing.

The import decisions, as mentioned above and also discussed in Andersson et al. (2008) and Kasahara and Rodrigue (2008), are usually associated with sunk and fixed costs, besides the usual transaction price. First-time importers need to learn customs procedures, search for potential foreign suppliers, testing whether the good matches current production line, negotiation, contract formulation etc. These cost could be high, especially considering the long distance and potential differences in language, business culture, legal system etc. Continuing importing is also associated with fixed costs due to custom documents, administration fees for custom clearance, business relationship maintenance, quality inspection etc. In the presence of import restriction such as during the data period in Colombia, importers also need to pay additional costs to get the import license and overcome the trade friction. All of these will be reflected as sunk and fixed costs of

\footnotetext{
${ }^{2}$ It will be great if we can evaluate the relative importance of these different channels of dynamic productivity effect. Unfortunately, without detailed information on technical supports received by individual importing firms and firm-level R\&D in the Colombia data, which is used in the empirical study, we are unable to distinguish the relative importance of these channels. This could be an interesting topic for future research. In this paper, the dynamic productivity effect thus contains the total productivity effect of importing from all these channels.
} 
importing and they may have a substantial impact on individual firm's import decisions. One second purpose of this paper is to evaluate how trade policies influence the import participation, productivity, and long-term payoff to individual firms by reducing/increasing the sunk and fixed costs of importing.

I estimate the dynamic model structurally using a plant-level data set from Colombia. It is shown that importing increases both the within-plant current period revenue and future productivity substantially, lending evidence to the existence of both static and dynamic effects of importing. Among all four industries investigated in this paper, being an importing firm increases its currentyear revenue positively by a lowest $22.47 \%$ in the other metal products industry and a highest $29.98 \%$ in the printing and publishing industry, indicating clear evidence of a static effect of importing based on quality and variety effect. At the same time, being an importer increases within-firm productivity in the next period positively from a lowest $0.54 \%$ in the printing and publishing industry to a highest $5.80 \%$ in the structural metal products industry. This positive productivity effect, on one hand, will be (partly) carried over to future periods through the Markov productivity evolution process. On the other hand, the increased productivity will also affect the firm's importing decisions for the future, which further have an impact on future productivity. Both of these two channels suggest a dynamic productivity effect of importing. The estimation result also shows more productive firms tend to participate in importing of intermediate inputs.

In the first counterfactual exercise, I evaluate the total gains to firms from importing and the relative contribution through the static revenue effect and dynamic productivity effect. I simulate the within-firm total gains from importing, defined as the difference between the firm value in the data and that in a conjectured autarky economy when firms are not allowed to import, for each of the four industries. Results suggest the total gains from importing are substantial and both static and dynamic effects are important sources of gains from importing intermediate inputs. It is shown that importing access in the data increases firm value significantly, by 11.92$23.79 \%$ in the four industries. It arises from immediately increased revenue and dynamically increased productivity, though their relative contribution varies across industries. Among the four industries, the dynamic effect alone increase firm value by $1.89-18.41 \%$. This accounts for a lowest share of the total gains from importing in the printing and publishing industry $(15.86 \%)$, and a highest share in the structural metal products industry $(89.24 \%)$.

I also conduct two sets of policy counterfactual experiments to evaluate how trade liberalization affects firm value. In the first set of policy counterfactual experiments, I evaluate the marginal effects of sunk and fixed costs of importing on firm value. We find that high sunk and fixed costs of importing act as a barrier for firms to import, which prevents them from enjoying the gains from importing. Import liberalization by reducing sunk and fixed costs of importing can increase firm value substantially. Taking pharmaceuticals industry as an example, counterfactual analysis shows reducing the sunk and fixed costs of importing simultaneously by $10 \%$ increases firm value by $0.67 \%$. We also confirm that two trade policies - one changes sunk costs only and the other changes fixed costs only - have very different quantitative impact on firm value. This arises from the different implication of sunk and fixed costs on the persistence of firms' importing 
decisions. In the second set of policy experiments, I evaluate the impact of another type of trade reduction, which reduces import tariff, on firm value. I find that reducing tariff rate by $17 \%$, as happened in Colombia from 1990 to 1992, increases firm value substantially by $2.48 \%-12.04 \%$ in the four industries we examined. The different impacts across industries are mainly driven by these industries' heterogeneity in productivity impact of importing and substitutability between imported and domestic inputs.

The last, yet very important, question is: why should the effect of exposure to trade through importing differ from that of exporting? The reason is that importing directly affects the production process and potentially has a substantial impact on the productivity of importers. In contrast, exporting only affects production indirectly through learning-by-exporting and changing demand. Therefore, importing affects firm productivity through a more direct way which is different from exporting. ${ }^{3}$ This implies that imports of intermediate inputs have to be accounted for when evaluating a trade policy. Since importing is usually positively correlated with exporting, to identify the effect of importing, I also control for exporting in the empirical exercise. To make sure that my estimate of the gains from importing is not due to exporting, I further conduct robustness checks by performing the same estimation on a subsample of firms which do not export. The subsample results are similar to what we find in the whole sample. This indicates that our results on the gains from importing are robust.

Several recent papers are closely related to my work. Our theoretical model is structurally based on Aw et al. (2011) which investigates the firms' export behavior. Our work differs from it in two ways. First, we consider firm/plant's import decisions which potentially can affect production, productivity, and profitability substantially. As discussed above, the import decisions directly affect firms' production process and potentially may have an even higher impact on firm productivity. Second and more importantly, we explicitly disentangle the total gains from importing into a static effect due to quality and variety effect, and a dynamic effect due to productivity gains. This analytical framework can be applied to evaluate the short- and longterm effects in other similar applications. Unlike the structural IO/trade approach of this paper, a recently emerging literature in Macro-trade also tries to disentangle the static and dynamic gains from trade based on different versions of Melitz (2003) model (Sampson, forthcoming; Perla et al., 2015; Impullitti and Licandro, 2015, for example). Our paper differs from this line of literature in that we focus on different channels of gains: while this literature investigates the gains from trade through selection, technology spillover, and resource reallocation, we focus on the gains from import through the static quality and variety effect and dynamic productivity improvement to importers. In this sense, we see our paper complementary to this literature to improve the understanding of gains from trade.

Kugler and Verhoogen $(2009,2012)$ emphasize the input quality effect of importing. They argue that the output quality could be improved by using imported inputs with higher quality, under

\footnotetext{
${ }^{3}$ Using Indian data, Khandelwal and Topalova (2011) find lower tariffs on final goods and lower tariffs on intermediate inputs both have positive effects on firm productivity, with input tariffs having a larger impact. This result implicitly points to the possibility that international trade of intermediate inputs may have a larger impact on firm productivity than international of final goods.
} 
the assumption that input quality and productivity are complementary to produce the output quality. Goldberg et al. (2009, 2010) and Halpern et al. (2011), on the other hand, emphasize the variety effect of importing. Goldberg et al. (2009, 2010) study how the increased availability of new input categories as a result of importing enhances the development of new products and thus increases the variety of final goods in India. Halpern et al. (2011) find that importing more varieties of intermediate inputs increases firm productivity. Kasahara and Lapham (2013) investigate the aggregate productivity gains of importing via resource reallocation in an extended Melitz model (Melitz, 2003), while assuming that the productivity of each particular firm is fixed. In contrast, my paper studies how importing improves the within-firm productivity and firm value of the importing firms. Compared with the three lines of literature ${ }^{4}$, another new feature of this paper is that I simultaneously estimate the gains from importing and endogenous importing decisions in a structural model. This model allows me to further evaluate the relative importance of the static effect and dynamic effect separately in terms of increased firm value.

The seminal work of Kasahara and Rodrigue (2008) and Ge et al. (2011) also estimate the effect of importing on firm productivity with the elements of static quality and variety effect and productivity effect. My paper extends their work by explicitly modelling firms' dynamic optimal decisions of import in a full dynamic model. This additional work brings several advantages. First, it allows us to evaluate the long-term gains from import in terms of discounted future profit explicitly. Because productivity influences firms' importing decisions and the importing decisions in turn influence future firm productivity and profitability dynamically, taking into account the endogenous importing decisions in a full dynamical model is a necessary step to fully capture the total long-term gains from importing. Second, due to similar reasons, the full dynamic model also provides a more accurate model-consistent prediction of firms' dynamic import decisions. Third, this paper quantitatively evaluates the relative importance of the static gains from importing due to the "Quality and Variety Effects" from that of the dynamic productivity effect, both in terms of contribution to long-term firm profit. Moreover, the structural model in my paper allows me to use counterfactual analysis to evaluate the effects of different policy changes (e.g. change of importing costs) on firms' profitability and importing dynamics. My paper also relates to Bøler et al. (2014), who also estimate a similar dynamic model of importing. While they focus on the complementarity between imports of intermediate inputs and R\&D in Norway, my paper focuses on evaluating the relative importance of static and dynamic effects, and on the elasticity of fixed/sunk importing costs on firm importing choice and firm value.

The remainder of this paper is organized as follows. Section 2 describes some basic facts in the Colombian data, which forms the basis for the theoretical model. Section 3 introduces a theoretical model to characterize firms' dynamic importing decisions. Section 4 describes the

\footnotetext{
${ }^{4}$ Besides the three lines of literature, several other papers also investigate the effect of importing, but from different angles. Bloom et al. (2012), for example, investigates how imports of Chinese final products affect the productivity in OECD countries due to competition effect. Goel (2012) and Glass and Saggi (2001), in contrast, focus on the effect of importing on employment and wage rate. Goel (2012) evaluates how imports of unskilled intermediates (offshoring) increase employment and wage-bills of both skilled and unskilled workers by inducing skill-biased technology. Glass and Saggi (2001) find increased outsourcing of production to a low wage country leads to a lower relative wage and a faster rate of innovation.
} 
empirical model and estimation strategy and section 5 reports the estimation results. Section 6 discusses the self selection of firms in importing, and section 7 performs counterfactuals to calculate the gains from importing and evaluate the gains from two types of import liberalization. Section 8 concludes.

\section{The Data}

The data set used in this paper is from the Colombian manufacturing census from 1977 to 1991, which was collected by the Departamento Administrativo Nacional de Estadistica (DANE). The census covers all plants in the manufacturing sector for 1977-1982, and all plants with ten or more employees after $1982 .{ }^{5}$ It contains detailed information about plants' expenditure on domestic intermediate input, imported intermediate input, output, investment, capital stock, wage expenditure, number of workers, and many other plant characteristics (e.g. age, ownership). For a detailed introduction to the data set, refer to Roberts and Tybout (1996) and Roberts and Tybout (1997).

This paper focuses on four industries in the empirical exercises. They are pharmaceuticals, printing and publishing, structural metal products, and other metal products. The choice of industries reflects several considerations. First, since we are going to investigate the effect of importing, we choose industries with relatively more importing firms. Second, all industries are important industries for the Colombian economy, with the number of observations in each of these industries large enough to do empirical investigation industry by industry. There are 12,164 observations in total for all four industries, with the number of observations varying from 1,793 to 5,355 for each industry.

We are particularly interested in the consumption of intermediate inputs and how much of them is imported from foreign countries. In the data, intermediate input refers to the summation from a list of inputs which the firm is allowed to write for "raw materials, materials, and packaging". This includes expenditure on raw materials such as cloth and gasoline, but does not include consumption of electrical energy, "general expenses" such as professional services and advertising, or "industrial expenses" such as spare or replacement parts, all of which are reported separately. Materials sold without transformation are also excluded. These inputs are all short-term. Firms are allowed to import some of their intermediate inputs from abroad and use both the domestic and imported intermediate inputs in their production ${ }^{6}$. We observe the expenditure on imported and domestic intermediate inputs separately in the data. Table 1 summarizes the mean and standard deviation for variables related to importing industry by industry. It is shown that importing of material inputs plays an important role in these industries, with the share of importing observations ranging from 21.37-71.56\% and expenditure share ranging from 27.95-62.82\% in these

\footnotetext{
${ }^{5}$ These plants are "manufacturing plants" instead of "(all) plants of manufacturing firms", according to page 229 in Roberts and Tybout (1996). As a result, it is very unlikely that they could be sales distribution hubs, which are classified in retail and wholesale sector.

${ }^{6}$ In our dataset, almost all firms spend positive amount on domestic material inputs. We treat those firms with zero or negative expenditure on domestic material input as misreporting and drop them. In all four industries in total, there are only 25 such observations out of 12,164 .
} 
four industries. Summary statistics of other variables used in this paper are also reported in Table 1.

I start with a description of several stylized facts observed in the data, which motivate this study and form the basis of the theoretical model in the following section. The first fact is that although the importing status is subject to considerable turnover, it is still quite persistent over time. Table 2 calculates the transition probability of importing status for the four industries. It indicates that for all firms that were not importing, on average about $5 \%$ start importing the next year and $95 \%$ stay not importing. Similarly, for all firms that were importing, on average about $11 \%$ stop importing at the end of that year, while $89 \%$ of them continue importing. This suggests while some shocks, such as shocks to productivity and importing costs in each period, drives the turnover of importing status, some other firm characteristics such as productivity and firm size ensure the persistence of importing status.

The second fact is that importers have higher labor productivity than non-importers, as shown in Table 3. In all of the four industries, the industry mean of labor productivity for importers is at least $67 \%$ higher than that for non-importers. As discussed above, this positive correlation could be due to self selection, static revenue effect, or dynamic productivity effect of importing. From the data pattern, however, we cannot tell which way the causality goes. That is, we don't know whether this productivity difference is because more productive plants tend to import intermediate inputs, or because importing increases productivity.

Figure 1 further investigates the relationship between importing history and firm labor productivity. To construct this figure, the observations were classified into several groups according to their importing history. For example, group 1 includes observations from firms that never import in the data and group 2 includes all observations that are the last year before importing 7. A comparison of group 1 and group 2 indicates obvious selection of importing based on labor productivity - firms that are about to starting importing are more productive than firms that never import in the data. Group 3, which includes all observations importing for the first time, contains the same set of firms as in group 2. Considering that it takes time for importing experience to affect firm technology/productivity, the jump of labor productivity from group 2 to group 3 reflects mainly the static effect — the new importing firms benefit from the higher quality and/or increased variety of imported intermediate inputs, which increases the current period revenue immediately ${ }^{8}$. In contrast, the increase of labor productivity from group 3 to group 4 may contain both a static revenue effect if the firm increases their import in the second year, and a lagged dynamic productivity effect from the importing experience in the first year. We may additionally use the import volume data to help distinguish these two effects. More interestingly, the average labor productivity of group 8 and 9 , which represent observations after

\footnotetext{
${ }^{7}$ The full definition of the groups are as follows: group 1 includes observations from firms that never import in the data and group 2 includes all observations that are the last year before importing; groups 3-6, respectively, collects observations of the first, second, third, and fourth year of importing; group 7 includes observations corresponding to $N \geq 5$ years of importing; group 8 corresponds to observations of the first year after stop importing; group 9 collects observations of $N \geq 2$ years after stopping importing. Note that all four industries are pooled together in figure 1 .

${ }^{8}$ Note that the labor productivity here is defined as revenue per worker.
} 
stopping importing, is still higher than that of group 2 before importing. ${ }^{9}$ This is consistent with the existence of a dynamic effect of importing — firms still benefit from their past importing experience even after stopping importing.

In the following sections, we are going to develop and estimate a dynamic structural model of endogenous importing decisions at the firm/plant level, which are consistent with these stylized facts.

\section{The Model}

In this section, I introduce a dynamic model to characterize plants' decisions to import intermediate inputs or rely solely on domestically-supplied inputs ${ }^{10}$, following the model developed by Aw et al. (2011), which was initially used to analyze firms' dynamic exporting decisions. An important feature of this model is that it considers both the determinants and effects of importing simultaneously. A new feature of the model in this paper is that it explicitly disentangles the static effect and the dynamic productivity effect of importing within one unified framework. These features allow us to investigate and quantify different sources of gains from importing.

\section{$3.1 \quad$ Timing}

Plants face monopolistic competition from other plants in the same industry, and the objective of each plant is to maximize its discounted value of lifetime profits. The timing of the information flow and decisions is as follows:

1. At the beginning of each date, each plant observes its own capital stock $\left(K_{j t}\right)$, productivity $\left(\omega_{j t}\right)$, and its importing status for the current date $\left(d_{j t}\right)$, as well as the aggregate demand and production shifter, $\gamma_{t}$. These variables are summarized in $s_{j t}=\left\{K_{j t}, \omega_{j t}, d_{j t}, \gamma_{t}\right\}$ which represents plant $j^{\prime} s$ state at date $t$.

2. Each plant chooses the amount of labor, domestic input, and imported input to maximize its period profit. Then production and sales occur.

3. Each plant then observes the realization of its own sunk cost and fixed cost of importing. I allow new importers to pay a potentially higher sunk cost of importing and continuing importers to pay a potentially lower fixed cost of importing. These two costs are i.i.d drawn from two different distributions.

4. Plants decide whether to import intermediate inputs next period based on their draw of

\footnotetext{
${ }^{9}$ Please be reminded that the firms in group 2 may be different from those from group 8 and 9 . So the comparison can only give a rough result. It will be much better if we look at the same class of firms if we have enough firms which start importing and then stop importing in the data period. Unfortunately, the number of such firms is too small so that no reliable inference can be based on that.

${ }^{10}$ The data do not link plants common to a firm, so we treat the plant as the decision-making unit. This is potentially problematic because, among multi-plant firms, plant-level imports may partly respond to characteristics of other plants. However, the vast majority of Colombian firms operate a single plant.
} 
sunk and fixed costs. If a plant decides to import next period, it pays the fixed cost if it is importing this period, or the sunk cost if it is not importing this period.

5. Plants choose investment. All state variables are updated and the next period begins.

\subsection{Technology and Demand}

The production function is Cobb-Douglas, with a nested CES function to combine the domestic and imported intermediate inputs. The nested CES function characterizes the static effect of importing through quality effect and variety effect. A nice feature of this parametrization is that the potential input quality effect and the input variety effect are explicitly represented by parameters in the production function. This is in the spirit of the Halpern et al. (2011). The production function is

$$
\begin{aligned}
Q_{j t} & =\exp \left(\omega_{j t}+\xi_{j t}\right)\left[L_{j t}^{\alpha_{l}} M_{j t}^{\alpha_{m}} K_{j t}^{\alpha_{k}}\right] \\
\text { with } M_{j t} & =\left[M_{j d t}^{\frac{\theta-1}{\theta}}+\left(A M_{j f t}\right)^{\frac{\theta-1}{\theta}}\right]^{\frac{\theta}{\theta-1}}
\end{aligned}
$$

where $\omega_{j t}$ is the productivity observed by plant $\mathrm{j}$ itself and $\xi_{j t}$ represents the i.i.d measurement error. $L_{j t}$ and $K_{j t}$ are labor and capital of plant $j$ at date $t . M_{j d t}$ and $M_{j f t}$ are domestic and imported inputs used to produce the intermediate input $M_{j t} . \theta$ is the corresponding elasticity of substitution of domestic and imported inputs. In some sense, $\theta$ represents the input variety effect of imported products because it governs how easily the imported inputs can be substituted by domestic ones in the production process. When $\theta$ is large, the two inputs are more substitutable, meaning that the input variety effect of the imported inputs is small. $A$ represents the input quality effect of the imported inputs relative to domestic inputs, whose quality coefficient is normalized to one. When $A=1$, imported inputs have no quality advantage over domestic inputs; when $A>1$, imported inputs have relative quality advantage over domestic inputs; when $A<1$, imported inputs have relative quality disadvantage. ${ }^{11}$

If plant $j$ is an importer of intermediate inputs, then the logarithm production function is

$$
\ln Q_{j t}=\alpha_{l} \ln L_{j t}+\alpha_{m} \frac{\theta}{\theta-1} \ln \left[M_{j d t}^{\frac{\theta-1}{\theta}}+\left(A M_{j f t}\right)^{\frac{\theta-1}{\theta}}\right]+\alpha_{k} \ln K_{j t}+\omega_{j t}+\xi_{j t}
$$

If plant $\mathrm{j}$ is not an importer, then the logarithm production function takes the more familiar form

$$
\ln Q_{j t}=\alpha_{l} \ln L_{j t}+\alpha_{m} \ln M_{j d t}+\alpha_{k} \ln K_{j t}+\omega_{j t}+\xi_{j t}
$$

\footnotetext{
${ }^{11}$ To identify the quality parameter, $A$, ideally we need the physical quantity of domestic and imported inputs, $M_{j d t}$ and $M_{j f t}$. However, in most cases researchers only have the value of inputs instead of physical quantity of inputs, as in this paper. In this case, the quality parameter $(A)$ we recover in the empirical exercise contains both the real quality effect and the price difference between domestic and imported inputs, $A=\frac{p_{d}}{p_{f}} \cdot$ (real quality effect parameter).
} 
Demand is assumed to be the classic Dixit-Stiglitz type:

$$
Q_{j t}^{D}=\Phi_{t} P_{j t}^{\eta}
$$

where $\eta$ is the demand elasticity, which is assumed to be common across products within one industry. $P_{j t}$ is plant j's price. $\Phi_{t}$ is the time-specific demand shifter common for all plants.

\subsection{Plants' Static Decision}

Plants produce differentiated products and face monopolistic competition in the output market. Based on the timing described above, labor, domestic and imported inputs are static variables and they depend on the beginning-of-date state $s_{j t}=\left\{K_{j t}, \omega_{j t}, d_{j t}, \gamma_{t}\right\}$. A plant's static optimization problem is to choose these static inputs to maximize its own period profit.

When $d_{j t}=1$, plant $j$ has access to the import market in the current period. Observing the input prices and the demand status, plant $j$ 's static problem is to choose the static inputs $\left(L_{j t}, M_{j t d}\right.$ and $\left.M_{j t f}\right)$ and output price to maximize its period profit. Specifically, plant needs to choose static inputs $\left(L_{j t}, M_{j t d}\right.$ and $\left.M_{j t f}\right)$ to minimize the cost of producing any amount of output; then, facing the plant level demand, the plant sets output price to maximize its period profit. Similarly, when $d_{j t}=0$, the plant has no access to the import market at date $t$; it chooses labor and domestic inputs to minimize the cost of producing any amount of output, and then chooses output price to maximize its period profit.

From plants' period profit maximization, we can derive the revenue function as a function of productivity, capital stock, current importing status, and a time-specific effect $\gamma_{t}$, which captures the demand shifter and time-specific input prices. Put in logarithm form,

$$
\ln R_{j t}=\gamma_{t}+r_{k} \ln K_{j t}+r_{\omega} \omega_{j t}+r_{d} d_{j t}
$$

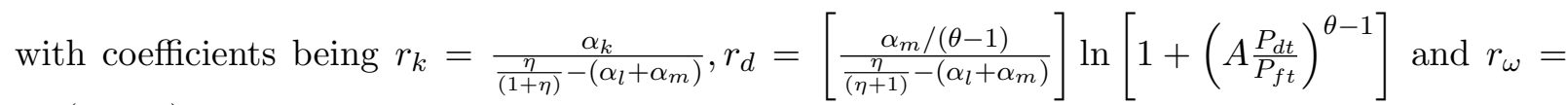
$\frac{\left(\alpha_{l}+\alpha_{m}\right)}{\frac{\eta}{(\eta+1)}-\left(\alpha_{l}+\alpha_{m}\right)}$. This equation shows that importing directly impacts current revenue through quality and variety effect of importing, even when the technology/productivity is not changed. The strength of the impact is $r_{d}$, which is a function of $A$ and $\theta$. This implies that the effect of importing on revenue depends on the strength of the input quality effect $(A)$ and input variety effect $(\theta)$ of imported inputs.

Under the demand and production assumptions above, total variable cost is a fixed share of revenue

$$
C_{j t}=\frac{1+\eta}{\eta}\left(\alpha_{l}+\alpha_{m}\right) R_{j t}
$$


The corresponding profit is a fixed share of the revenue

$$
\pi_{j t}=\left[1-\frac{1+\eta}{\eta}\left(\alpha_{l}+\alpha_{m}\right)\right] R_{j t}
$$

Note that equations (4) and (5) are generalizations of equations (6) and (7) in Aw et al. (2011), in which the marginal cost is assumed to be constant $\left(\alpha_{l}+\alpha_{m}=1\right)$. In their paper, the demand elasticity can be directly estimated from data on total variable cost and revenue. In this paper, if $\alpha_{l}+\alpha_{m}$ is known, then the demand elasticity $\eta$ can also be estimated similarly from data on revenue and total variable cost. ${ }^{12}$

\subsection{Dynamic Choice of Importing Status}

Observing sunk and fixed costs, each plant's dynamic optimization problem is to decide whether or not to import materials in order to maximize its own continuation value. The main considerations of importing participation are gains from importing, the fixed cost of continued importing, and the sunk startup costs of importing. Previous importing status is relevant because first-time importers need to pay the sunk cost $\left(C_{j t}^{s}\right)$ and continuing importers instead pay the fixed cost $\left(C_{j t}^{f}\right)$ to import. The sunk cost may be much higher than the fixed cost. Assume that the sunk cost and fixed cost are i.i.d draws from two different distributions, $C_{j t}^{s} \sim F^{s}$ and $C_{j t}^{f} \sim F^{f}$. They provide one source of exogenous shocks to the firm importing decisions.

The productivity $\left(\omega_{j t}\right)$ follows a first order Markov process

$$
\begin{aligned}
\text { Productivity } & : \omega_{j t}=E\left(\omega_{j t} \mid \omega_{j t-1}, d_{j t-1}\right)+\varepsilon_{j t} \\
& =g\left(\omega_{j t-1}, d_{j t-1}\right)+\varepsilon_{j t}, \text { with iid } \varepsilon_{j t} \sim N\left(0, \sigma_{\varepsilon}^{2}\right)
\end{aligned}
$$

where the innovation of the Markov process $\varepsilon_{j t}$ is drawn from a normal distribution with mean 0 and variance $\sigma_{\varepsilon}^{2}$. The productivity shock provides another source of exogenous variation to firm importing decisions. A new feature is that historical importing experience $d_{j t-1}$ affects future productivity evolution process endogenously. If a firm was an importer at date $t-1$, its productivity will be enhanced due to the importing experience. This increased productivity further affects future importing decisions, which in turn has an impact on future productivity. This embodies the idea that importing intermediate inputs has a dynamic effect on productivity. Since the importing decisions are endogenous, this setup implies that productivity is endogenous.

Next-period capital stock $\left(K_{j t+1}\right)$ equals the current investment $\left(i_{j t}\right)$ plus current capital stock after depreciation: $K_{j t+1}=\left(1-\rho_{k}\right) K_{j t}+i_{j t}$, where $\rho_{k}$ is the depreciation rate. Assume all distributions and the evolution of the dynamic variables are common information. Plant $j$ 's firm

\footnotetext{
${ }^{12}$ Refer to a separate online appendix for details about deriving equations (3), (4) and (5).
} 
value before it observes the current date fixed cost and sunk cost is

$$
\left.V\left(s_{j t}\right)=\iint\left[\pi_{(} s_{j t}\right)+\max _{d_{j t+1}}\left\{V^{1}\left(s_{j t}\right)-d_{j t} C_{j t}^{f}-\left(1-d_{j t}\right) C_{j t}^{s}, V^{0}\left(s_{j t}\right)\right\}\right] d F^{s} d F^{f}
$$

where $V^{1}\left(s_{j t}\right)$ and $V^{0}\left(s_{j t}\right)$ are discounted choice specific continuation values of importing and not importing, respectively, assuming that each plant always chooses optimal investment associated with its importing status. $d_{j t}$ is a discrete $0 / 1$ variable identifying firm j's importing status at date $t$. Importing decision is dynamic through two channels: productivity channel and cost channel ${ }^{13}$. On one hand, current importing decision affects future productivity. On the other hand, current importing status determines what costs, sunk or fixed, the firm pay to import in the next period. If the firm imported at date $t$, then it will pay a fixed cost $C_{j t}^{f}$ to continue importing at date $t+1$. If the firm did not import at date $t$, then it will pay a sunk cost $C_{j t}^{s}$ (very likely higher than fixed cost) to start importing.

Note that the value of investment is subsumed in the choice-specific value functions $V^{1}\left(s_{j t}\right)$ and $V^{0}\left(s_{j t}\right)$. To be more precise the choice specific value functions could be written as

$$
\begin{aligned}
& V^{1}\left(s_{j t}\right)=\delta E_{t} V\left(s_{j t+1} \mid s_{i t}, d_{j t+1}=1\right) \\
& V^{0}\left(s_{j t}\right)=\delta E_{t} V\left(s_{j t+1} \mid s_{i t}, d_{j t+1}=0\right)
\end{aligned}
$$

where $\delta$ is the discount factor. The expectation is taken over the stochastic evolution process of productivity $\omega_{j \tau}$ for all $\tau \geq t+1$, and uncertainty about the demand shifter and input prices $\gamma_{\tau}$ for all $\tau \geq t+1$. More specifically, by expressing expectation in integral form, the choice-specific value functions are written as:

$$
\begin{aligned}
& V^{1}\left(s_{j t}\right)=\delta \max _{I_{j t}} \iint V\left(s_{j t+1}, d_{j t+1}=1\right) d F\left(\omega_{j t+1} \mid \omega_{j t}, d_{j t}\right) d F\left(\gamma_{t+1} \mid \gamma_{t}\right) \\
& V^{0}\left(s_{j t}\right)=\delta \max _{I_{j t}} \iint V\left(s_{j t+1}, d_{j t+1}=0\right) d F\left(\omega_{j t+1} \mid \omega_{j t}, d_{j t}\right) d F\left(\gamma_{t+1} \mid \gamma_{t}\right)
\end{aligned}
$$

Equations (8) and (9) give the optimal investment decision rule, $I_{j t}=I_{t}\left(\omega_{j t}, k_{j t}, d_{j t+1}\right)$, which is a function of productivity, capital, and future importing status. Equations (7), (8) and (9) together fully characterize plants' importing decisions under each state $s_{j t}$ and can be used to evaluate the payoff to plants for each choice under each state. In the empirical exercise, for simplicity I assume the time dummy $\gamma_{t}$ to be a constant in the dynamic estimation.

\section{Estimation Strategy}

I observe in the data the value of domestic material, imported material, a 0/1 importing indicator $^{14}$, capital, investment, number of employees, wage expenditure, revenue and other plant char-

\footnotetext{
${ }^{13}$ Ramanarayanan $(2011,2013)$ also writes a model of firms' importing decision which depends on productivity and other factors and use the model to study the gains from import in the latter. In their model, firms' choose importing decision to maximize static profit.

${ }^{14}$ The importing indicator equals 1 if the imported material is positive. It is zero otherwise.
} 
acteristics (e.g. age and ownership). The parameters to be estimated include: $\alpha_{l}, \alpha_{m}, \alpha_{k}, \eta, A, \theta$, $g(\cdot), \sigma_{\varepsilon}^{2}, F^{s}, F^{f}$. The parameters of major interest in this paper are the input quality effect parameter $A$, the input variety effect parameter $\theta$, the productivity evolution process $g(\cdot)$, and the distributions of sunk cost and fixed cost $\left(F^{s}\right.$ and $\left.F^{f}\right) . A$ and $\theta$ represent the static productivity effect of importing due to input quality effect and input variety effect. $g(\cdot)$ helps quantify the dynamic productivity effect associated with importing.

Timing of events is important for identifying the model parameters, because the model setup is based on it. Given the timing assumption, the source of identification is intuitive. Roughly speaking, the static revenue effect intuitively is identified by comparing the revenue of firms that import for the first year and that from the year before importing (group 2 and 3 in Figure 1), after controlling for productivity as shown in Eq. (3). The dynamic effect is identified by comparing the productivity between the first and second year of importing (group 3 and 4 in Figure 1). Specifically, the increase of revenue in group 4 contains both the lagged productivity effect from their importing experience for the first year and the immediate static revenue effect from importing in the second year. By controlling for the size of immediate revenue effect using the import volume, we can separate the lagged productivity effect. The selection can be identified by comparing the productivity of observations of last year before importing and that of firms which never import (group 1 and 2 in Figure 1).

More specifically, the demand and production parameters, as well as the parameters governing the productivity evolution process, can be identified from plants' static decisions. Specifically, information from plants exclusively using domestic inputs can help identify the share parameters $\alpha_{l}, \alpha_{m}, \alpha_{k}$ in the production function and the parameters associated with $\omega_{j t-1}$ in the productivity evolution process $g(\cdot)$. On the other hand, usage of imported and domestic materials from importing plants provides additional information to help identify the quality parameter $A$, the elasticity of substitution $\theta$, and the parameters associated with $d_{j t-1}$ in the productivity evolution process $g(\cdot)$. Usage of imported and domestic materials from importing plants also provides information about the share parameters $\alpha_{l}, \alpha_{m}, \alpha_{k}$ and $g(\cdot)$, which can be used to improve the estimation efficiency. Given the estimates for $\alpha_{l}$ and $\alpha_{m}$, the demand elasticity can be identified from the cost and revenue information.

Finally, the distributions of sunk cost and fixed cost can be identified from plants' dynamic decisions on whether or not to import intermediate inputs. Specifically, the average size of fixed and sunk costs of importing are identified from the portion of firms which imports. If the sunk and fixed costs is generally small, we should observe a large share of firms which import. Otherwise, the share of importing firms should be small. In addition, the relative size of fixed and sunk costs of importing are identified from the turnover rate of importing. If sunk cost is larger than fixed cost, we should observe that once a firm starts importing, it is very likely that it will continue importing in the next period. In other words, the persistence of importing status will be very strong. In contrast, if the sunk cost is smaller than the fixed cost, we expect to observe that many firms quit importing and then start importing in order to get the smaller sunk cost. 
The estimation algorithm combines the insights of Olley and Pakes (1996) and Das et al. (2007). First, I estimate the production parameters $\alpha_{l}, \alpha_{m}, \alpha_{k}, A$, and $\theta$, using data on labor, capital, domestic and imported inputs and investment. Then given the estimates of $\alpha_{l}$ and $\alpha_{m}$, the demand elasticity is estimated from equation (4), using variable cost and revenue data. The profit function can be derived from the estimate of the revenue function from equations (3) and (5). Finally, the sunk and fixed costs parameters are estimated from plants' decisions on whether to import intermediate inputs. More precisely, the cost parameters can be identified from the conditional choice probabilities (CCP) of that plants begin or stop importing intermediate inputs.

\subsection{Production and Productivity Evolution Parameters}

The parameters of production function and productivity evolution process include $\alpha_{l}, \alpha_{m}, \alpha_{k}, A, \theta, g(\cdot)$, and $\sigma_{\varepsilon}^{2}$. In order to increase estimator efficiency, I make use of the data on all plants (both importers and non-importers) to estimate the production parameters, although the identification of $\alpha_{l}, \alpha_{m}, \alpha_{k}$ does not rely on information about importers. Denoting $x=\ln X$ and making use of the importing status dummy $d_{j t}$ for firm $\mathrm{j}$ at date t, equation (1) and (2) can be rewritten in one equation as:

$$
q_{j t}=\alpha_{l} l_{j t}+\alpha_{m} \frac{\theta}{\theta-1} \ln \left[M_{j d t}^{\frac{\theta-1}{\theta}}+\left(A M_{j f t}\right)^{\frac{\theta-1}{\theta}} d_{j t}\right]+\alpha_{k} k_{j t}+\omega_{j t}+\xi_{j t}
$$

This equation allows us to use input and output data for all plants to estimate the production parameters. $\omega_{j t}$ constitutes the plant-level productivity observed by the plant (but not by researchers), and $\xi_{j t}$ is iid measurement error not observed by the plant and researchers. By assumption, $\xi_{j t}$ is independent with $l_{j t}, k_{j t}, M_{j d t}, M_{j f t}$, and $d_{j t}$. However, it is a well known fact that the direct OLS estimator from the above equation is subject to an endogeneity problem because the labor and material inputs choices are dependent on $\omega_{j t}$. In addition, the importing status $d_{j t}$ is also correlated with $\omega_{j t}$ because productivity is a Markov process. This correlation further aggravates the endogeneity problem.

To ensure a consistent estimator, the above endogeneity problem must first be resolved. In general, plants' investment contains information about the unobserved productivity $\omega_{j t}$. Under the timing assumption in this paper, investment is a function of current capital stock, productivity, and the chosen importing status for the future, i.e. $i_{j t}=i_{t}\left(\omega_{j t}, k_{j t}, d_{j t+1}\right)$. We can utilize the insights of Olley and Pakes (1996) to recover the unobserved productivity $\omega_{j t}$ from investment, 
$\omega_{j t}=\omega_{t}\left(i_{j t}, k_{j t}, d_{j t+1}\right)$, under the usual monotonicity assumption. ${ }^{15}$

$$
\begin{aligned}
q_{j t} & =\alpha_{l} l_{j t}+\frac{\alpha_{m} \theta}{\theta-1} \ln \left[M_{j d t}^{\frac{\theta-1}{\theta}}+\left(A M_{j f t}\right)^{\frac{\theta-1}{\theta}} d_{j t}\right]+\alpha_{k} k_{j t}+\omega_{t}\left(i_{j t}, k_{j t}, d_{j t+1}\right)+\xi_{j t} \\
& =\alpha_{l} l_{j t}+\alpha_{m} \frac{\theta}{\theta-1} \ln \left[M_{j d t}^{\frac{\theta-1}{\theta}}+\left(A M_{j f t}\right)^{\frac{\theta-1}{\theta}} d_{j t}\right]+\phi\left(i_{j t}, k_{j t}, d_{j t+1}\right)+\xi_{j t}
\end{aligned}
$$

where $\phi\left(i_{j t}, k_{j t}, d_{j t+1}\right)$ captures the combined effect of capital and observed productivity on production. The static input shares $\widehat{\alpha_{l}}$ and $\widehat{\alpha_{m}}$, the quality parameter $\widehat{A}$, the variety parameter $\widehat{\theta}$, and the $\phi(\cdot)$ function can be estimated from equation (11) semiparametrically ${ }^{16}$. This estimation is consistent since $l_{j t}, M_{j d t}, M_{j f t}, i_{j t}, k_{j t}$ and $d_{j t+1}$ are all uncorrelated with $\xi_{j t}$. In this paper, $\phi\left(i_{j t}, k_{j t}, d_{j t+1}\right)$ is parameterized as a cubic function. Denote $\widehat{\phi}_{j t}$ as the fitted value for $\phi\left(i_{j t}, k_{j t}, d_{j t+1}\right)$; then productivity can be expressed as $\omega_{j t}=\widehat{\phi}_{j t}-\alpha_{k} k_{j t}$. Substituting $\omega_{j t}$ in the production function with $\omega_{j t}=g\left(\omega_{j t-1}, d_{j t-1}\right)+\varepsilon_{j t}$ and replacing $\omega_{j t-1}$ with $\omega_{j t-1}=\widehat{\phi}_{j t-1}-\alpha_{k} k_{j t-1}$ yield an estimation equation:

$$
\widehat{\phi}_{j t}=\alpha_{k} k_{j t}+g\left(\widehat{\phi}_{j t-1}-\alpha_{k} k_{j t-1}, d_{j t-1}\right)+\varepsilon_{j t}+\xi_{j t}
$$

This equation can be estimated semi-parametrically. The parameter $\alpha_{k}$ and the $g(\cdot, \cdot)$ function can be retrieved from data on $\widehat{\phi}_{j t}, \widehat{\phi}_{j t-1}, k_{j t-1}$, and $d_{j t-1}$. In this paper, the $g(\cdot, \cdot)$ function is parameterized simply by $g\left(\omega_{j t-1}, d_{j t-1}\right)=g_{0}+g_{\omega} \omega_{j t-1}+g_{d} d_{j t-1}$. $g_{\omega}$ represents the marginal effect of current productivity on future productivity, and $g_{d}$ represents the dynamic effect of importing on productivity associated with importing. We are especially interested in $g_{d}$ and we expect it to be positive based on our model. In the empirical exercise, I also estimated an extend model in which I control for export decision in the productivity Markov process, $\omega_{j t}=g\left(\omega_{j t-1}, d_{j t-1}, e_{j t-1}\right)+\xi_{j t}=g_{0}+g_{\omega} \omega_{j t-1}+g_{d} d_{j t-1}+g_{e} e_{j t-1}+\xi_{j t}$. Here $e_{j t-1}$ is the discrete $0 / 1$ exporting indicator with $e_{j t-1}=1$ if the firm $\mathrm{j}$ is importing at $t-1$. The parameter $g_{e}$ is associated with $e_{j t-1}$. I will estimate both the baseline model and extended model in the empirical exercise.

Based on the estimate of $\alpha_{k}$, we can construct a pseudo sample of productivity for each plant each year

$$
\widehat{\omega_{j t}}=\widehat{\phi}_{j t}-\widehat{\alpha_{k}} k_{j t}
$$

Note that if deflated revenue is used to proxy the output quantity in the estimation, as in the empirical exercise in this paper, the recovered productivity is revenue-based (R-TFP in Foster

\footnotetext{
${ }^{15}$ To recover $w_{j t}$ by inverting investment function, a critical condition is that investment is strictly increasing in productivity, which is a popular assumption in the literature. Intuitively, investment should (at least weakly) increase in productivity. However, a sound econometric test of the validity of the assumption is still called for. Levinsohn and Petrin (2003) instead uses intermediate inputs to control for productivity. Ackerberg et al. (2006) further develops a new approach based on timing assumption on the choice of inputs, in which all parameters are estimated in one stage, to solve the potential collinearity problem in the first stage estimation in Olley and Pakes (1996).

${ }^{16}$ Note that by assumption, the iid shocks of the sunk and fixed costs of importing provide independent variation between the investment decision and the choices of labor, material, and $d_{j t}$. So this paper is not subject to the collinearity problem in the first stage estimation of Olley and Pakes (1996), which was pointed by Ackerberg et al. (2006). The author thanks Paul Schott for pointing this out.
} 
et al. (2008)).

\subsection{Demand Elasticity and Profit Function}

Plants' static decisions lead to a simple relationship between the total variable cost and the revenue, as shown in equation (4). The total variable cost is defined as the total expenditure on domestic inputs, imported inputs and labor and is observed in the data. By introducing the usual optimization error and measurement error, equation (4) can be written in the following estimable form:

$$
C_{j t}=\frac{1+\eta}{\eta}\left(\alpha_{l}+\alpha_{m}\right) R_{j t}+\zeta_{j t}
$$

The error term $\zeta_{j t}$ is assumed to be i.i.d across plants and over time. As in Das et al. (2007) and Aw et al. (2011), we can estimate the demand elasticity $\eta$ from equation (14), given that $\alpha_{l}$ and $\alpha_{m}$ have been estimated above.

Construct the profit function. With all the estimates of production and demand parameters in hand, we can compute the revenue function parameters $r_{k}, r_{w}$, and $r_{d}$ in equation (3). To derive the full revenue function, we still need to estimate the coefficients of the time dummies. Denote $\widetilde{r}_{j t}=r_{j t}-\left(r_{w} \widehat{\omega_{j t}}+r_{k} k_{j t}+r_{d} d_{j t}\right)$. The coefficients of time dummies can be estimated from the following equation:

$$
\widetilde{r}_{j t}=\gamma_{t}+e_{j t}
$$

where the error term $e_{j t}$ comes from an i.i.d measurement error or any form of optimization error which affects plant revenue.

The revenue function is then $R_{j t}=\exp \left(\gamma_{t}+r_{k} k_{j t}+r_{w} \omega_{j t}+r_{d} d_{j t}\right)$. The profit, as a fixed share of the revenue function from equation (5), is a function of $\left(\gamma_{t}, w_{j t}, k_{j t}, d_{j t}\right)$,

$$
\pi_{j t}=\left[1-\frac{1+\eta}{\eta}\left(\alpha_{1}+\alpha_{2}\right)\right] \exp \left(\gamma_{t}+r_{k} k_{j t}+r_{w} \omega_{j t}+r_{d} d_{j t}\right)
$$

where all unknown parameters are replaced with their estimates. This profit function is useful when computing the value functions of plants in the next subsection.

\subsection{Sunk/Fixed Cost Parameters}

The distributions of sunk cost and fixed cost, in principle, can be identified from plants' dynamic discrete decisions of importing status. A maximum likelihood estimator (MLE) is constructed for estimating the distribution of both sunk and fixed costs in this section. As I am using a short panel data, it is hard to estimate the evolution process of the macroeconomic environment dummy, $\gamma_{t}$. In the dynamic estimation I treat the $\gamma_{t}$ as a constant over time for simplicity. ${ }^{17}$

\footnotetext{
${ }^{17}$ In fact, the variation of $\gamma_{t}$ over time is reasonably small for all four industries in question. For Parmaceutical industry, $\gamma_{t}$ ranges from 4.56 to 4.93 , and the standard deviation of the estimates ranges from 0.21 to 0.22 . For
} 
The conditional probability of observing a data point with $d_{j t+1}=1$, given state $s_{j t}=\left\{\omega_{j t}, k_{j t}, d_{j t}\right\}$ is

$$
\begin{aligned}
L_{j t}^{1} & =\operatorname{Pr}\left\{d_{j t+1}=1 \mid s_{j t}\right\} \\
& =\operatorname{Pr}\left\{d_{j t} C_{j t}^{f}+\left(1-d_{j t}\right) C_{j t}^{s} \leq V^{1}\left(s_{j t}\right)-V^{0}\left(s_{j t}\right) \mid s_{j t}\right\}
\end{aligned}
$$

The conditional probability of observing a data point with $d_{j t+1}=0$ is $1-L_{j t}^{1}$. The probability of observing importing status $d_{j t+1}$ is

$$
L_{j t}=d_{j t+1} L_{j t}^{1}+\left(1-d_{j t+1}\right)\left(1-L_{j t}^{1}\right)
$$

Under the i.i.d assumption on fixed and sunk costs of importing, the probability of observing a specific importing history of plant $\mathrm{j}$ is

$$
L_{j}=\prod_{t=1: T} L_{j t}
$$

The probability of observing the importing status of all plants in the data set is

$$
L=\prod_{j=1: N} L_{j}=\prod_{j=1: N} \prod_{t=1: T} L_{j t}
$$

Given the parametric assumption on the distributions of sunk and fixed costs, parameters in $F^{s}$ and $F^{f}$ could be estimated using MLE. In this paper, I assume that sunk costs and fixed costs are i.i.d drawn from two different exponential distributions, $C_{j t}^{s} \sim \exp (c s)$ and $C_{j t}^{f} \sim \exp (c f)$. Then the distribution parameters $\left(\lambda_{s}=\log (c s), \lambda_{f}=\log (c f)\right)$ can be estimated by MLE. The major problem associated with this estimation is that $V^{1}\left(s_{j t}\right)$ and $V^{0}\left(s_{j t}\right)$ need to be constructed for each parameter iteration from the plants' dynamic optimization problem, as specified in equations (7), (8), and (9). The computational algorithm to solve for $V^{1}\left(s_{j t}\right)$ and $V^{0}\left(s_{j t}\right)$ is summarized in the Appendix A.

\section{$5 \quad$ Estimation Results}

In this section, I will first report and briefly discuss the estimation results of the empirical model from the plant-level Colombian data. I use the unbalanced panel data to structurally estimate the dynamic model. I drop the first year for new firms and the last year for exiting firms to ensure that for each observation the lagged and leading variables, in particular importing status $d_{j t-1}$

printing and publishing industry, $\gamma_{t}$ ranges from 3.80 to 4.04, and the standard deviation of the estimates ranges from 0.12 to 0.13 . For structural metal industry, $\gamma_{t}$ ranges from 2.56 to 3.01, and the standard deviation of the estimates ranges from 0.19 to 0.21 . For other metal industry, $\gamma_{t}$ ranges from 2.53 to 2.88 , and the standard deviation of the estimates ranges from 0.12 to 0.13 . In general the intra-industry variation of $\gamma_{t}$ is small and they are not statistically significantly different from each other. Moreover, although $\gamma_{t}$ affects the level of revenue (and as a result profit and long-term firm value), its effect on the ratio of the estimated gains from import relative to firm value is small because $\gamma_{t}$ emerges on both the numerator and denominator and the level effects can be canceled out mostly. So we think this simplification does not cause a big problem. 
and $d_{j t+1}$, are fully observed. ${ }^{18}$ I then use the unbalanced data to estimate the dynamic model of importing decisions as well as the productivity evolution process.

\subsection{Production and Productivity Evolution}

Table 4 reports the estimates of production parameters derived from (11) and (12). I also add plant age and ownership into the $\phi(\cdot)$ to control for plant-specific characteristics in the regression. ${ }^{19}$ Age is the number of years in operation and ownership is a dummy variable which equals 1 if the plant is a public corporation and 0 otherwise ${ }^{20}$. The magnitude of the estimated output elasticities, $\alpha_{l}, \alpha_{m}$, and $\alpha_{k}$, are all in reasonable range. The estimated return to scale, defined as the sum of the three output elasticities, is very close to one for all four industries. The ratio of labor to capital output elasticities is larger in the labor-intensive printing and publishing industry, and smaller in the capital-intensive pharmaceuticals industry.

We are particularly interested in the quality parameter $(A)$ and elasticity of substitution $(\theta)$. In all four industries, the input quality parameters $A$ are all not statistically different from 1. However, we must be cautious about how to interpret this result. As we estimate the model using the value of imported and domestic inputs, the estimated quality parameter $(A)$ contains both the real input quality effect and the price difference between domestic and imported inputs. So an estimate of $A$ close to one means the imported intermediate inputs have no obvious quality advantage in all these industries after adjusting for price difference. Or in other words, the price difference of imported and domestic intermediate inputs reflects their quality difference, corroborating earlier studies such as Kugler and Verhoogen (2012). To separate the real input quality effect from the price difference, we need additional information on prices of both imported and domestic inputs. Unfortunately, these data are not available in the Colombian data; therefore, in the paper, the parameter $A$ is interpreted as containing both the input quality effect and the price difference between imported and domestic inputs. Another interesting finding is that the elasticity of substitution $\frac{\theta-1}{\theta}$ is smaller than one. This implies that the variety effect of imported inputs does exist, which is consistent with the argument in Markusen (1989) and Goldberg et al. $(2009,2010)$ that domestic and imported intermediate inputs are complements to each other.

The estimates of productivity evolution process are recorded in Table 5. The estimation is based on (12). The results from the baseline model are reported in panel $\mathrm{A}$ in Table $5 . g_{\omega}$ is the effect of today's productivity $\left(\omega_{j t}\right)$ on tomorrow's productivity $\left(\omega_{j t+1}\right) \cdot g_{d}$ measures the dynamic effect of importing status on future productivity. In panel B of Table 5, I also control for the

\footnotetext{
${ }^{18}$ This paper shut down entry/exit in order to focus on the importing decisions, and this is a simple way to play around the first-year/last-year problem. An alternative way of dealing with this problem is to explicitly consider entry/exit in the model. Given that our focus is on the gains from importing to existing firms after controlling for endogenous importing decisions, abstracting away from entry/exit does not seem to cause a big problem. However, we do recognize that extensive margin due to entry/exit can contribute to the expansion of international trade as in Hummels and Klenow (2005) and Kehoe and Ruhl (2013) for example.

${ }^{19}$ As a robustness check, we also estimate the model without controlling for age and ownership in the $\phi(\cdot)$ function. The results are both qualitatively and quantitatively similar and we report the results in Table A3.

${ }^{20}$ For clarity, the estimates of the non-parametric $\phi(\cdot)$ function are not reported in the data. In practice, I used a polynomial up to third order to approximate it in the estimation.
} 
export dummy in the productivity evolution process, as captured by $g_{e}$. The parameter $\sigma_{\omega}$ is the standard deviation of the productivity shock, which is assumed to be normally distributed $N\left(0, \sigma_{\omega}^{2}\right)$ in the estimation.

Both regressions yield consistent qualitative results. First, importing has a positive and statistically significant effect on productivity evolution $\left(g_{d}>0\right)$. If a plant imports today, its future productivity will be improved significantly. Second, productivity evolution in all industries is quite persistent over time ( $g_{\omega}$ is above 0.8 in all industries). If a plant is productive today, it is very likely that tomorrow it will continue to be productive.

If we compare the quantitative magnitude of the estimates in these two regressions, we find that both regressions in general generate quantitatively similar estimates for all key parameters - in the sense that the estimates of $g_{d}, g_{\omega}$ and $\sigma_{\omega}$ are all of similar magnitude in both regressions. As the most important parameter of our interest, $g_{d}$ ranges from 0.0097 in the printing and publishing industry to 0.0589 in the structural metal products industry in Panel A when we do not control for exporting. After controlling for exporting in Panel B, it ranges from 0.0054 in printing and publishing industry to 0.0580 in the structural metal products industry. We can see that they are of similar magnitude. However, in general the effect is relatively smaller, though very slightly, after controlling for exporting. This might be due to a potential positive correlation between importing and exporting. The estimated effect of importing would have picked up the effect of exporting if exporting is not controlled for in the baseline model. I will rely on the results from panel B to compute the dynamic effect of importing. After controlling for exporting, being an importer this year can improve the next period productivity by $1.09 \%$ in the pharmaceuticals industry for example. This productivity effect could be as large as $5.80 \%$ in the structural metal products industry.

Figure 2 simulates how importing dynamically affects the expected within-firm productivity in 30 years for each of these industries. I compute the expected productivity based on the estimated productivity evolution process for firms which do not import and for those which always import. In the first column of Figure 2, the starting productivity was chosen at the $10 \%$ quintile of each industry, lower than the steady state productivity implied by the Markov productivity process. Compared with firms that do not import, firms that always import-as characterized by the solid curve-not only have a higher growth rate of productivity during the transition period, but also have a higher level of productivity at steady state. Being always importing increases the within-firm productivity in the steady state significantly, by $3.53 \%, 3.25 \%, 13.84 \%$, and $4.78 \%$ in these four industries, respectively. Similarly, in the second column, the starting productivity was chosen at the $90 \%$ quintile of each industry, higher than the steady state productivity. We find the productivity of firms that always import goes down more slowly in the transition process with a higher level at steady state, compared with firms that do not import.

I also ran two regressions to check the robustness of dynamic productivity effect of importing to different measures of import. In both regressions, I use import expenditure share, instead of importing dummy, to measure the effect of importing on productivity. The first regression is 
the baseline model without controlling for export, while in the second export is controlled for using an export dummy. In both regressions, I found a positive and significant effect of importing on productivity. These results are summarized in Table A1. These observations confirm the conjecture in the model section that importing has a positive dynamic effect on productivity. We will compute the gains of firm value from this dynamic effect in section 8 .

\subsection{Demand Elasticity and Revenue Function}

The demand elasticity can be estimated from equation (14) given output elasticity of labor and material. The results are reported in Panel $\mathrm{C}$ of table 5. The estimated demand elasticity is significantly less than -1 . This is reasonable because the market power in the monopolistic competition market allows plants to charge a markup price. Under the structural assumptions of production and demand, plants' revenue and profit functions can be constructed using (3) and (5). This is useful for estimating dynamic parameters and constructing firm value in the next subsection.

I report the revenue function parameters, $r_{\omega}, r_{k}$ and $r_{d}$, for each of the four industries in Table 6 . The standard errors are computed from 200 draws from the parameter estimates of production function and demand elasticity. It is shown that importing on average can increase the currentperiod revenue by about $22.47 \%-29.98 \%$ in these four industries, suggesting that importing firms can benefit from a combination of the improved quality and/or increased variety of imported inputs immediately. The positive effect of importing on current revenue corroborates the result in Kasahara and Rodrigue (2008). This is the source of static effect of importing. I will quantify by how much it increases firm value in Section 7 . Meanwhile, $r_{\omega}$ is the revenue elasticity of

productivity. For example, $r_{\omega}=1.6948$ in pharmaceuticals industry implies that a $1 \%$ increase in productivity increases current period revenue by $1.6948 \%$. Similarly, $r_{k}=0.1556$, as the revenue elasticity of capital, implies a $1 \%$ increase in capital stock increases revenue by $0.1556 \%$. Because profit is a fixed share of revenue given the Dixit-Stiglitz demand function, this table shows that a firm can increase its profit by increasing its productivity, capital size, and by using imported intermediate inputs of higher quality or more variety.

\subsection{Distribution of Sunk and Fixed Costs}

As noted above, the distribution parameters of the fixed and sunk costs can be estimated with Maximum Likelihood, using plants' dynamic decisions on whether or not to import intermediate inputs. To limit the range of the parameters in the estimation, I redefine $\lambda_{s}=\log (c s), \lambda_{f}=$ $\log (c f)$ and estimate the parameters $\lambda_{s}$ and $\lambda_{s}$ in the Matlab program.

The estimates of $\lambda_{s}$ and $\lambda_{f}$ are reported in Table 7. It is shown that, first, the draw of sunk costs of importing could be quite large, which serves as a big barrier for plants to start importing. Conditional on importing, those firms actually import in the data bear a sunk costs of importing 
ranges from 176 thousand in printing and painting industry ( $8.17 \%$ of yearly profit) to as high as 940 thousand for Parmaceutical industry (34.17\% of yearly profit) in 1986 US dollars if they are first-time importers. In the other two industries, the sunk costs are 898 thousand for structural metal industry and 696 thousand for other metal industry also in 1986 US dollars. These estimates are of similar order of magnitude as that reported in Kasahara and Lapham (2013), which reports a sunk cost of importing ranging from 459 thousand 1990 US dollars for Plastic Products to 874 thousand 1990 US dollars for food products using Chilean plant-level data. Compared with the export sunk costs estimated in Das et al. (2007) using the same Colombia plant-level dataset, the sunk costs of import is also comparable and even larger, presumably reflecting the fact that Colombian firms faced very strict import friction but much smaller export friction during the data period. Secondly, the estimate of the fixed cost parameter $\lambda_{f}$ is significantly smaller than that of sunk cost parameter $\lambda_{s}$ in all four industries. This implies sunk cost appears to be always larger than fixed cost in all of these industries, which is consistent with the idea that new importers need to invest additionally to start importing. In order to maintain the same import probability as above, the firms actually import in the data pay a fixed costs of importing ranging from 3.58 thousand (about $0.17 \%$ of yearly profit) for printing and publishing industry to as high as 36.73 thousand (about $1.34 \%$ of yearly profit) for pharmaceutical industry in 1986 US dollars, which are much smaller compared with sunk costs.

The large sunk and fixed costs of importing reflect both the explicit and hidden costs of importing to firms. As Andersson et al. (2008) point out, importing is associated with fixed costs that are sunk, because import agreement is preceded by a search process for potential foreign suppliers, inspection of goods, testing whether the good matches current production streamline, negotiation, contract formulation etc. These costs may be very high. Also, first time importers need to spend both human and monetary resources to learn customs procedures. This again increases the sunk cost. As for the fixed cost, continuing importers do not need to pay costs to master the customs procedures, and they have more experience in importing. So we expect that fixed cost will be much lower than sunk cost, as shown in the estimation results. However, fixed costs could still be high due to different reasons. First, continuing importers still need to maintain the business relationship with their trade partners via different forms, which may be costly. Second, although first-time importers have inspected the goods, they still need to inspect goods each time they continue importing in order to make sure that the international exporters deliver the appropriate materials. Moreover, the estimated sunk and fixed costs parameters also pick up the import frictions due to trade policy. For example, in Colombia there were quota and license restrictions on some products for importing, as documented in Roberts and Tybout (1996). As a result, plants planning to import need to spend extra time and resources (both monetary and non-monetary) to lobby importing licenses, legally or illegally. All of the quota-induced costs related to importing are picked up by the fixed/sunk costs estimated in the model and can contribute to the large estimated sunk/fixed costs.

The fact that the sunk cost is much larger than the fixed cost is consistent with our model conjecture that sunk cost is a critical factor that generates the observed persistence of plants' 
importing status. A new importing firm need to pay the sunk cost to start importing. In contrast, a continuing importing firm pays the fixed cost, which is on average much smaller than the sunk cost. This explains why compared to non-importers, importers today are more likely to import tomorrow. Also, the large sunk costs prevent non-importers from starting to import. Only those non-importers who have a very small draw of the sunk cost start importing. This explains that why only a few non-importers start importing at each period.

\subsection{Robustness Check}

Our goal is to accurately measure the effects of importing intermediate materials on productivity and firm value. As such, it is important to have confidence that the estimation results from the model are robust and not sensitive to particular underlying assumptions in the model. In particular, we need to make sure that the estimated effect of importing is not actually the effect of exporting, considering the possible correlation between the two activities. To remove the impact of exporting on the estimation results, I estimate the model for non-exporters only and its results then are compared with those estimated by using the whole sample. ${ }^{21}$

Tables A2 reports the estimates of the model parameters using the subsample with only nonexporters. The estimation results are both qualitatively and quantitatively similar to that estimated using the whole sample. First of all, the production parameters are of similar magnitude. Second, importing as expected has a positive impact on productivity in the non-exporter subsample. In the Markov productivity evolution process, the coefficient of the importing dummy ranges from 0.0086 to 0.0458 , which is again of similar magnitude to that estimated using the full sample. Importing also has a positive impact on revenue, with the coefficient ranging from 0.1444 to 0.3550 . This is again close to that found in the full sample. Finally, the estimates of the distribution parameters of sunk and fixed costs are similar to that derived in the full sample - in the sense that their magnitude is similar and that sunk cost parameters are significantly larger than fixed cost parameters. These results show that the estimated effect of importing on revenue and productivity is robust and that the estimated effect of importing is actually not the effect of exporting.

\footnotetext{
${ }^{21}$ For this robustness check to be valid, we need to rule out the possibility that the plants in the remaining non-exporter subsample may be sales distribution hubs. Thank the referee for pointing this out. We can rule out this possibility from the following evidence. First, These plants are "manufacturing plants" instead of "(all) plants belonging to manufacturing firms", according to page 229 in Roberts and Tybout (1996). Second, the import probability in the non-exporter subsample is substantially lower than that in the full sample. In the subsample it is $62.1 \%, 19.0 \%, 17.6 \%$, and $27.7 \%$ for the four industries, which are substantially lower than that in the full sample as reported in Column 2 in Table 1. Third, the import-revenue ratio conditional on importing in the non-exporter subsample is very close to that in the full sample. For the four industries, this ratio is $20.3 \%, 15.0 \%, 16.8 \%$, and $21.8 \%$ in the subsample, contrast to $16.9 \%, 16.2 \%, 16.1 \%$, and $22.6 \%$ in the full subsample. This suggests that the non-exporter plants are unlikely to be sales distribution hubs, because otherwise they should have much higher import probability and import-revenue ratio conditional on importing.
} 


\section{Self Selection}

As part of the model, the dynamic policy function of plants' optimal importing decisions is also estimated within the structural model. The importing status choice is determined by the comparison between the involved fixed or sunk costs of importing and the net benefit of importing in terms of expected firm value. From the dynamic model developed above, a non-importing plant in state $s_{j t}=\left(\omega_{j t}, k_{j t}, d_{j t}=0\right)$ chooses to start importing if and only if its draw of sunk cost is smaller than the expected gain associated with importing,

$$
C_{j t}^{s} \leq V^{1}\left(s_{j t}, d_{j t}=0\right)-V^{0}\left(s_{j t}, d_{j t}=0\right)
$$

where $V^{1}\left(s_{j t}, d_{j t}=0\right)$ and $V^{0}\left(s_{j t}, d_{j t}=0\right)$, as functions of $s_{j t}$ given $d_{j t}=0$, are choice-specific value functions corresponding to choosing $d_{j t+1}=1$ and $d_{j t+1}=0$, respectively. This condition determines the threshold sunk cost for current non-importers to start importing. Similarly, a current importer with state $s_{j t}=\left(\omega_{j t}, k_{j t}, d_{j t}=1\right)$ chooses to continue importing if and only if its draw of fixed cost is smaller than the expected gains from continuing to import,

$$
C_{j t}^{f} \leq V^{1}\left(s_{j t}, d_{j t}=1\right)-V^{0}\left(s_{j t}, d_{j t}=1\right)
$$

where $V^{1}\left(s_{j t}, d_{j t}=1\right)$ and $V^{0}\left(s_{j t}, d_{j t}=1\right)$ are the choice-specific firm value when the current importer continues import and when it does not, respectively. This condition determines the threshold cost involved in current importers' decision of whether or not to continue importing.

The choice-specific firm values on the right hand side of (20) and (21) are functions of the state variables $s_{j t}=\left(\omega_{j t}, k_{j t}, d_{j t}\right)$. They are defined in (8) and (9) and are all estimated within the dynamic model along with the dynamic estimation of parameters. So the importing decisions depend on firm's state $s_{j t}=\left(\omega_{j t}, k_{j t}, d_{j t}\right)$ and its draw of i.i.d sunk or fixed costs of importing. In particular, the i.i.d draw of sunk and fixed costs of importing and transitory productivity shock together provides exogenous variations of the turnover of importing status. Meanwhile, the persistence of productivity and capital stock, and the fact that sunk cost is larger than fixed cost of importing together ensure the persistence feature of importing status over time. Empirical results show that productivity and sunk/fixed costs of importing are the major determinants of firm-level importing status. Firms with high productivity and low importing costs will import. Meanwhile, although in general larger firms are more likely to import, we find that capital stock does not affect the importing decision much after conditioning on productivity.

Figure 3 plots the importing decisions for each of the four industries. The left column is the importing decision of firms that are currently not importing and the right column is for firms that are importing. The horizontal and vertical axis represent productivity and sunk/fixed costs of importing, respectively. The curves are the break-even points in (20) and (21). Firms that are below these curves will import, because their gains from importing is larger than the sunk/fixed costs of importing. This result suggests obvious selection based on productivity and sunk/fixed costs of importing - more productive firms with low importing costs tend to import. 


\section{Gains from Importing Intermediate Inputs}

This section performs three counterfactual experiments based on the structural model. These three experiments serve three purposes: to quantify the within-plant gains from importing intermediate inputs, to evaluate the relative contribution of importing through the static revenue effect and a dynamic productivity effect, and to quantify the marginal effect of import costs on firm value.

\subsection{Total Gains from Importing}

The within-plant total gains from importing intermediate inputs is defined as a firm's value in the data when it has access to the foreign import market minus the firm value of the same plant in a counterfactual autarky economy. An autarky refers to an economy in which none of the plants have access to a foreign market. The autarky plant value can be easily derived by solving the following standard investment model

$$
\begin{aligned}
V\left(\omega_{j t}, K_{j t}\right) & =\pi\left(\omega_{j t}, K_{j t}\right)+\delta \max _{i_{j t}} E_{\omega_{j t+1}} V\left(\omega_{j t+1}, K_{j t+1}\right) \\
\text { s.t. } K_{j t+1} & =i_{j t}+\left(1-\rho_{k}\right) K_{j t} \\
\omega_{j t+1} & =E\left(\omega_{j t+1} \mid \omega_{j t}\right)+\varepsilon_{j t+1}
\end{aligned}
$$

It is straightforward that the solution to the autarky model is equivalent to our full model with infinite fixed and sunk costs for importing. Using this idea, we can easily calculate the autarky plant value from our full model by letting the sunk and fixed costs be infinite. The total gains from importing intermediate inputs can be calculated as

$$
\text { Total gain }=V\left(s_{j t}\right)-V\left(\omega_{j t}, K_{j t}\right)
$$

Note that allowing firms to import inputs globally, as a option, increases firms' value even when they are not importing currently. The possibility to use this option to import in the future in the case of having a good productivity shock or a good draw of sunk cost of importing increases a firm's expected future profit, even when it is not importing currently.

One limitation of this exercise is that we implicitly assume that the intermediate input prices will not change when computing firm value in the autarky economy, which is not ideal in practice. In fact, the intermediate input price would very likely be higher in the autarky economy, because firms cannot import from abroad. As a result, firm value in the autarky economy would be even lower and the true total gains from importing should be even larger. So we should treat the total gains calculated in (23) as the lower bound of gains from importing.

In order to evaluate the average within-firm gains from importing for each industry, I compute the gains for each observation in the data given its state variable $\left(\omega_{j t}, k_{j t}, d_{j t}\right)$, using the formula in (23) based on counterfactual analysis. Table 8 reports the industry mean of total gains from 
importing intermediate inputs for each industry, in terms of increased firm value. The first two columns report the industry mean of firm value in the data and in the autarky economy, respectively. The last two columns calculate the increased firm value or its percentage change as a result of importing. It is shown that, compared with autarky, importing access in the data increases firm value substantially from $11.92 \%$ in printing and publishing industry to as high as $23.79 \%$ in pharmaceuticals industry.

I also plot the kernel density distribution of the firm value in the data and in the autarky economy separately, for each of the four industries in Figure 4. In the figure, the solid curve is the kernel density estimation of firm value in the observed data, and the dot-dashed curve is that for the autarky. It is shown that the firm value in the data stochastically dominates that in the autarky, further supporting the idea that importing access in the data increases firm value comparing with the autarky economy.

It is worth noting that in the policy experiment, in order to simply the structural estimation we follow Aw et al. (2011) to abstract away from the general equilibrium effect on material input prices, other input prices, and output prices. This may bias the quantitative results. However, compare with the first order effect calculated in this paper, the general equilibrium is of second order and its effect should be smaller. In Section 7.5 we discuss this question in more detail and perform two sets of tests to show that our results are robust enough to the time dummy in the revenue function, which captures the general equilibrium effect.

\subsection{Static and Dynamic Gains from Importing}

In this subsection, I decompose the importing gains into the static effect and the dynamic effect, by simulating several modified versions of the full model.

When there is no dynamic effect of importing, $g_{d}=0$. We can solve the full dynamic model under the restriction $g_{d}=0$ to derive a new plant value, $V\left(s_{j t} \mid g_{d}=0\right)$, which does not contain the dynamic effect. I define the gains from dynamic effect as the difference between the firm value in the full model and $V\left(s_{j t} \mid g_{d}=0\right)$,

$$
\text { Dynamic Effect }=V\left(s_{j t}\right)-V\left(s_{j t} \mid g_{d}=0\right) \text {. }
$$

Then the static effect can be computed as the difference between the value of a firm when it has access to importing but has no dynamic effect, $V\left(s_{j t} \mid g_{d}=0\right)$, and the firm value in the autarky economy, $V\left(\omega_{j t}, K_{j t}\right)$,

$$
\text { Static Effect }=V\left(s_{j t} \mid g_{d}=0\right)-V\left(\omega_{j t}, K_{j t}\right) \text {. }
$$

By definition, the sum of dynamic effect and static effect equals the total gains from importing. I compute the counterfactual firm value, $V\left(s_{j t} \mid g_{d}=0\right)$, for each observation in the data first. Then I can derive the dynamic effect and static effect using (24) and (25), for each data point. 
The industry means of static and dynamic gains from importing, in terms of firm value, are reported in Table 9. It is shown that both dynamic and static effects are important in these industries, although their relative importance varies among industries. For example, in pharmaceuticals industry the dynamic productivity effect alone increases firm value by $5.93 \%$, while the static effect derived from improved quality and variety of intermediate inputs increases firm value by $17.86 \%$, suggesting that both of them are important sources of gains from importing. In contrast, the static effect is relatively more important in printing and publishing industry, in which the static effect increases firm value by $10.03 \%$ compared with $1.89 \%$ for dynamic effect. As a comparison, dynamic effect is relatively more important in structural metal products industry. It increases firm value by $18.41 \%$ while static effect contributes a increase of firm value by $2.22 \%$ only. The cross-industry variation of the relative importance of the static and dynamic effect reflects the different magnitude of productivity effect and quality and variety effect reported in Table 4 and 5. In printing and publishing industry when price-adjusted quality parameter $A$ is the smallest (close to 1), the static effect is small. In contrast, in structural metal industry the productivity effect of importing is the highest, it is dynamic effect is large.

I also plot the kernel density estimation of the counterfactual firm value without dynamic effect, $V\left(s_{j t} \mid g_{d}=0\right)$, in Figure 4 industry by industry. It stochastically dominates the density of the autarky firm value, but it is stochastically dominated by that in the data with both static and dynamic effects. In general, both Table 9 and Figure 4 suggest that both static effect and dynamic effect are important sources of gains from importing - although their relative importance may depend on the characteristics of the industry. One key implication is that we have to consider firms' gains from importing both in the short term and in the long term when evaluating the effect of an importing policy, because firms can benefit from importing both statically when they are importing and dynamically even after they stop importing. If we only include the static effect, we will inadvertently underestimate the gains from importing.

\subsection{Policy Counterfactual I: Sunk/Fixed Costs of Import and Firm Value}

The fight between trade protection and trade liberalization has been pervasive in the history of international trade, and it is still popular even nowadays for both economic and political reasons. In this subsection, I examine the effect of a specific type of import liberalization/protection, by quantifying the marginal effect of sunk and fixed costs of importing on firm value in the presence of both static and dynamic effects of importing. The sunk/fixed-costs-associated import liberalization/protection has an impact on expected firm value by changing firms' current and future importing decisions, as indicated by the model. This work is done by performing counterfactual analysis based on the dynamic structural model.

In Panel A of Table 10, I examine the effect of import liberalization on firm value. I reduce the mean of both costs in Panel B of Table 10 by 5\%,10\%, 25\%, and 50\% separately, while keeping other primitive parameters unchanged, and compute their effect on firm value in each of the four industries. When there is a $5 \%$ reduction of both costs, the firm values in these four industries 
are reduced by $0.33 \%, 0.35 \%, 0.73 \%$, and $0.51 \%$, respectively. The effect on firm value increases nonlinearly when we reduce these costs further. When reducing both costs by $50 \%$, the firm value increases more significantly by $3.53 \%, 4.56 \%, 9.91 \%$, and $5.83 \%$. Again, I plot the kernel density estimation of firm value after reducing both the sunk and fixed costs by $25 \%$ and $50 \%$ separately in Figure 6 industry by industry. We find that reducing costs of importing shifts the distribution of firm value to the right. This suggests a negative effect of importing costs on firm value, again consistent with the findings in Table 10.

Similarly, Panel B quantifies the effect of a increased import protection on firm value, as embodied by the increased sunk and fixed costs of importing. Based on the data, I increase the mean of both sunk and fixed costs by 5\%,10\%, 25\%, and 50\% and solve the model again to compute the firm value in each of these cases, while keeping other primitive parameters unchanged. It is shown that a $5 \%$ increase of both sunk and fixed costs decreases firm value by $0.33 \%$ in pharmaceuticals, $0.34 \%$ in printing and publishing, $0.69 \%$ in structural metal products, and $0.49 \%$ in other metal products. As the costs of importing becomes larger, this effect becomes larger. When both costs are increased by $50 \%$, the firm values in these four industries are reduced by $3.14 \%, 2.84 \%$, $5.67 \%$, and $4.42 \%$ in the above four industries, respectively. As a example, I plot the kernel density estimation of firm value when increasing both the sunk and fixed costs by $25 \%$ and $50 \%$ in Figure 5 industry by industry. It is shown that increasing costs of importing shifts the distribution of firm value to the left, suggesting a negative effect of importing costs on firm value.

As implied by our model, the relative magnitude of sunk and fixed costs of importing predicts different persistence of importing behavior. In particular, high sunk cost implies high persistence of importing status; in contrast, high fixed cost implies low persistence of importing status. As a result, trade policies that reduce sunk and fixed costs separately may have very different implication on plants' importing decisions and as a result gains from importing. ${ }^{22}$ We perform two sets of counterfactual experiments, by changing sunk costs and fixed costs of importing separately, to evaluate the different effects on firm value of government policies that changing sunk and fixed costs separately. The results are reported in Table 11. The results first confirm that sunk costs and fixed costs have different impact on gains from importing, although their relative importance varies across industry and also depends on the size of costs change. For example in pharmaceuticals industry a $5 \%$ reduction of fixed costs alone increases firm value by $0.26 \%$ while the same percentage reduction of sunk cost only increases firm value by $0.07 \%$. A similar pattern is observed in the other metal products industry. In the other two industries, the relative impact of sunk and fixed costs varies depending on the strength of policy change. A second interesting result is that the policy impact is nonlinear to policy strength. When the fixed costs of importing is reduced by from $5 \%$ to $50 \%$, the firm value increases slightly more than proportionally in all four industries. This nonlinear change, however, is much stronger for sunk costs-related policies. When the sunk costs of importing is reduced by from $5 \%$ to $50 \%$,

\footnotetext{
${ }^{22}$ Impullitti et al. (2013) show a similar mechanism at play for export decisions in a version of the Melitz model with post entry productivity uncertainty. They find that while a reduction in the fixed export costs makes the export decision more persistent, lowering sunk export costs reduces export persistence. Although their model differs from ours, a similar mechanism is at play in both models. We thank a anonymous referee for bringing out this interesting discussion to us.
} 
for example in Parmaceuticals, the increase of firm value changes from $0.07 \%$ to $0.86 \%$, which is much more than proportional change. This pattern holds in all four industries. The third interesting finding is that the relative impact of a reduction of fixed costs, compared with sunk costs, rises in the magnitude of sunk and fixed costs. If we rank the size of costs from lowest $(-50 \%)$ to high $(+50 \%)$ in Table 11, the relative impact on gains due to a change of fixed costs rises, as reported in Part III of Table 11. These differences arise from the fact that sunk costs and fixed costs plays different roles in determining firms importing decisions.

Our estimation results have important implications for trade policy, especially for developing countries. As we know, developing countries on average set more barriers in international trade. The large gains from importing access and the significant effect of importing costs on firm value suggest that developing countries can benefit from opening their markets to more actively import intermediate inputs. Moreover, as the cost/risk of a policy change is usually short-term, the government faces an intertemporal tradeoff between the long-term gain and short-term cost of a trade policy change. The finding that dynamic effect is significant suggests even when the static gains from importing (through input quality effect and input variety effect) is smaller than the cost of trade, the government may still find it beneficial to encourage importing if the dynamic gain is large enough. Moreover, the relative effectiveness of fixed cost-reduction policy and sunk cost-reduction policy suggests that government need to carefully choose from these two policy tools if they have a choice.

\subsection{Policy Counterfactual II: Import Tariff Reduction and Firm Value}

A tariff reduction reduces the relative prices of imported inputs compared with domestic alternatives, and as a result, increases the price-adjusted import quality (parameter $A$ in the model). This results in higher benefit of importing, leading to more firms participating in importing and higher volume of import conditional on importing. In the second counterfactual, I evaluate the effect of an import tariff reduction on firm value in the long run.

To simplify the analysis, we assume complete tariff pass through and that a $1 \%$ import tariff cut reduces the import-domestic price ratio by the same percentage. Then the new price-adjusted import quality is

$$
A_{\text {new }}=\frac{1+\tau}{1+\tau_{\text {new }}} A,
$$

where $A$ and $A_{\text {new }}$ are, respectively, the price-adjusted import quality estimated in the data and that implied by the new tariff rate in the counterfactual. $\tau$ and $\tau_{\text {new }}$ are the tariff rate in the data period and that in the counterfactual, respectively.

In Colombia there is a radical change of import tariff at the very end of our data period. The average import tariff rate drops from about $\tau=27 \%$ in the data period to about $\tau_{\text {new }}=10 \%$ after the data period in 1992 and thereafter. Given this tariff change, we calculate the new price-adjusted import quality $A_{n e w}$, re-solve firms' static and dynamic decisions, and calculate the resulting change of firm value. The results are reported in Table 12. As shown in the 
fourth row, a $17 \%$ drop of tariff increases the average firm value substantially by $2.48 \%$ in the pharmaceuticals industry to as high as $12.04 \%$ in the structural metal products industry. We also find that the impact of the tariff reduction on firm value varies substantially across industries. In the structural metal and other metal products industries, the impacts are much larger. This is reasonable because on one hand the domestic and imported inputs are more substitutable in these two industries (higher elasticity of substitution $\theta$ reported in Table 4). Firms in these two industries can benefit more because they can easily substitute their domestic inputs by the imported inputs after tariff reduction. On the other hand, the higher effect of import on productivity in these two industries, as reported in Table 5, also contributes to the higher gains from tariff reduction. I report the effects on firm value of more moderate and more radical changes of tariff rate in the other rows of Table 12. They are calculated in the same way as above. The cross-industry pattern of gains from tariff reduction is similar to above, and higher tariff reduction leads to substantially higher gains of firm value.

\subsection{Discussion of the Results}

We made several assumptions in order to make the model tractable and focus on our main question. Here we discuss the costs and benefits of making these assumptions and their potential impact on our main results.

Dynamic Export Decisions. It is worthy of noticing that in order to simplify the model and focus on firms' importing decisions, we abstract away from firms' dynamic export decisions. While this simplification saves us from modeling export demand ${ }^{23}$ and reduces the computation burden substantially, it may bias the estimates of gains from import downwards. In principle, export may amplify the gains from import because it gives the firm another opportunity to further explore the benefits from importing. So abstracting away firms' export decisions may underestimate the gains from import.

Importer-Exporter Linkage. Another potential limitation of this setup is that while importing decisions may also be affected by its trading partners who are exporters in foreign countries, especially if the Colombian importers are sales distribution hubs of their foreign parent firms, we abstract away from it due to lack of linked importer-exporter information. ${ }^{24}$ We think this is reasonable because evidence shows that it is very unlikely that these plants are sales distribution hubs of their foreign headquarters as will be discussed in detail in Section 5.4. So we treat Colombian importers as independent decision-making units in this paper. We think it is still very informative to understand firm importing and production decisions given that these plants are not sales distribution hubs and that the majority of Colombian firms are single-plant firms (Das et al., 2007).

General Equilibrium Effect. The model presented in this paper is a standard single-agent

\footnotetext{
${ }^{23}$ Due to lack of export price data, unfortunately we are unable to estimate the export demand separately from domestic demand without adding more assumptions.

${ }^{24}$ We thank one anonymous referee for pointing this out to us.
} 
dynamic model and as a result the general equilibrium effect is abstracted away. For example, in a standard CES preference case the demand shifter $\Phi_{t}$, which determines the intercept of the revenue function $\gamma_{t}$, is a function of the industry aggregate price and output in general equilibrium. We abstract away this general equilibrium effect in the model and treat $\gamma_{t}$ as a (exogenous) time dummy. Because in the empirical analysis the estimates of $\gamma_{t}$ over time are statistically not different from each other, we used their mean as the intercept of the revenue function following Aw et al. (2011). One big advantage of doing so is that we do not have to solve the dynamic general equilibrium model with many heterogeneous agents facing both idiosyncratic and aggregate uncertainties. Another advantage is that we do not have to track the evolution of these general equilibrium-related time dummies, so it reduces the state space by one dimension.

These two advantages together, as a result, help to reduce the computation burden substantially in the dynamic estimation and related counterfactual experiments.

The remaining question is: how sensitive are our results to the level of time dummy intercept in the revenue function which captures the general equilibrium effect? Without the hassle of explicitly extending the model to include general equilibrium condition, I perform two sets of experiments to shed light on this question. In the first set, I use the maximum of the estimated time dummies as the intercept of revenue function and recalculate the (1) gains from import, (2) gains from reduction of sunk and fixed costs of import, and (3) gains from tariff reduction. In the second set, I use the minimum of the estimated time dummies instead. The results are reported in Table A4-A6. The predictions of (1)-(3) in these experiments are very close to those in the full model, in which the mean of the estimated time dummies is used as the revenue intercept.

\section{Conclusion}

This paper investigates the effect of importing intermediate inputs on firm value and productivity, by estimating a dynamic model of endogenous importing decisions with random sunk and fixed costs of importing. This dynamic structural model allows me to empirically quantify the total gains from importing intermediate inputs, to separate the static and dynamic gains from importing, and to quantify the effect of import liberalization on firm value.

Empirical results using Colombian plant-level data show that importing increases both the withinplant current period revenue (static effect) and future productivity (dynamic effect) substantially, and that more productive plants with low importing costs tend to import intermediate inputs. Counterfactual analysis shows that, compared with the autarky economy, importing access in the Colombian data increases within-plant firm value substantially, which is defined as the accumulated future profit combining both static and dynamic effects. In the four industries we investigated, importing access improves firm value by $11.92-23.79 \%$ compared with autarky. It is also shown that both effects, the static effect via improved quality and variety of imported intermediate inputs and dynamic effect through productivity gain, are important sources of gains from importing. In these four industries, the dynamic effect alone increases within-firm value by $1.89-18.41 \%$, which accounts for about $15 \%-89 \%$ of the total gains from importing. It is also 
shown that import liberalization, either through reduction of sunk and fixed costs of importing or tariff reduction, affects firm value significantly by changing firms' endogenous importing choices. These results have important implications for trade policies. 


\section{References}

Acharya, R. C. And W. Keller (2009): "Technology Transfer through Imports," The Canadian Journal of Economics, Vol. 42, pp. 1411-1448.

Ackerberg, D. A., K. Caves, and G. Frazer (2006): "Structural Identification of Production Function," Working paper, UCLA Economics Department.

Amiti, M. And J. Konings (2007): “Trade Liberalization, Intermediate Inputs, and Productivity: Evidence from Indonesia," American Economic Review, 97, 1611-1638.

Andersson, M., H. LÖÖF, And S. Johansson (2008): "Productivity and International Trade: Firm Level Evidence from a Small Open Economy," Review of World Economics, 144, 774-801.

Aw, B. Y., M. Roberts, And D. Y. Xu (2011): "R\&D Investment, Exporting, and Productivity Dynamics," American Economic Review, 101, 1312-1344.

Bernard, A. B., J. B. Jensen, And P. K. Schott (2009): "Importers, Exporters and Multinationals: A Portrait of Firms in the U.S. that Trade Goods," in Producer Dynamics: New Evidence from Micro Data, ed. by T. Dunne, J. B. Jensen, and M. J. Roberts, Chicago: University of Chicago Press, $513-552$.

Blalock, G. And F. Veloso (2007): "Imports, Productivity Growth, and Supply Chain Learning," World Development, Volume 35, Issue 7, pp. 1134-1151.

Bloom, N., M. Draca, and J. V. Reenen (2012): "Trade Induced Technical Change: The Impact of Chinese Imports on Innovation, Diffusion and Productivity," Centre for Economic Performance Working Paper No. 1000.

Bøler, E. A., A. Moxnes, And K. H. Ulltveit-Moe (2014): "R\&D, International Sourcing and the Joint Impact on Firm Performance," working paper.

Coe, D. T. And E. Helpman (1995): "International R\&D Spillovers," European Economic Review, 39, 859-887.

Coe, D. T., E. Helpman, and A. W. Hoffmaister (1997): "North-South R\&D Spillovers," The Economic Journal, 107(440), 134-149.

Das, S., M. J. Roberts, And J. R. Tybout (2007): "Market Entry Costs, Producer Heterogeneity and Export Dynamics," Econometrica, 75, 837-873.

Eaton, J. And S. Kortum (2002): "Technology, Geography, and Trade," Econometrica, 70, 1741-1779.

EthieR, W. J. (1982): "National and international returns to scale in the modern theory of international trade," The American Economic Review, 72(3), 389-405.

Foster, L., J. Haltiwanger, and C. Syverson (2008): "Reallocation, Firm Turnover, and Efficiency: Selection on Productivity or Profitability?" American Economic Review, 98, 394425.

Ge, Y., H. Lai, and S. C. Zhu (2011): "Intermediates Import and Gains from Trade Liberalization," working.

Glass, A. J. AND K. SAGgi (2001): "Innovation and wage effects of international outsourcing," European Economic Review, 45, 67-86. 
Goel, M. (2012): "Does Offshoring Lift All Boats? The Role of Induced Technology Adoption and Innovation," working paper.

Goldberg, P., A. Khandelwal, N. Pavcnik, and P. Topalova (2009): "Trade Liberalization and New Imported Inputs," American Economic Review, 99, 494-500.

Goldberg, P. K., A. K. Khandelwal, N. Pavcnik, and P. Topalova (2010): "Imported Intermediate Inputs and Domestic Product Growth: Evidence from India," The Quarterly Journal of Economics, 125 (4), pp. 1727-1767.

Grossman, G. M. And E. Helpman (1991): "Innovation and Growth in the Global Economy," Cambridge, MA: The MIT Press.

Halpern, L., M. Koren, And A. Szeidl (2011): "Imported Inputs and Productivity," Center for Firms in the Global Economy (CeFiG) Working Papers.

Hummels, D. And P. J. Klenow (2005): "The Variety And Quality Of A Nation's Exports," American Economic Review, 95, 704-723.

Impullitti, G., A. A. Irarrazabal, And L. D. Opromolla (2013): "A theory of entry into and exit from export markets," Journal of International Economics, 90, 75C90.

Impullitti, G. And O. Licandro (2015): "Trade, Firm selection, and Innovation: The Competition Channel," mimeo.

Kasahara, H. And B. Lapham (2013): "Productivity and the Decision to Import and Export: Theory and Evidence," Journal of International Economics, Vol. 89, pp. 297-316.

Kasahara, H. and J. Rodrigue (2008): "Does the use of imported intermediates increase productivity? Plant-level evidence," Journal of Development Economics, 87, 106 - 118.

Kehoe, T. J. And K. J. Ruhl (2013): "How Important Is the New Goods Margin in International Trade," Journal of Political Economy, 121, 358-392.

Keller, W. (2004): "International Technology Diffusion," Journal of Economic Literature, 42, $752-782$.

Khandelwal, A. And P. Topalova (2011): "Trade Liberalization and Firm Productivity: The Case of India," The Review of Economics and Statistics, 93 (3), 995-1009.

Kugler, M. And E. Verhoogen (2009): "Plants and Imported Inputs: New Facts and an Interpretation," American Economic Review, 99, 501-07. 339.

Levinsohn, J. And A. Petrin (2003): "Estimating Production Functions Using Inputs to Control for Unobservables," The Review of Economic Studies, 70, 317-341.

Markusen, J. R. (1989): "Trade in Producer Services and in Other Specialized Intermediate Inputs," The American Economic Review, Vol. 79, No. 1, 85-95.

Melitz, M. J. (2003): "The Impact of Trade on Intra-Industry Reallocations and Aggregate Industry Productivity," Econometrica, 71, 1695-1725.

Olley, G. S. And A. Pakes (1996): "The Dynamics of Productivity in the Telecommunications Equipment Industry," Econometrica, 64, 1263-1297. 
Perla, J., C. Tonetti, And M. E. Waugh (2015): "Equilibrium Technology Diffusion, Trade, and Growth," mimeo.

Ramanarayanan, A. (2011): "Imported Inputs and International Trade Dynamics," Federal Reserve Bank of Dallas, working paper.

_ (2013): "Imported Inputs and the Gains from Trade," Tech. rep., Working Paper.

Roberts, M. J. And J. R. Tybout (1996): "Industrial Evolution in Developing Countries: Micro Patterns of Turnover, Productivity, and Market Structure," Oxford ; New York : Published for the World Bank by Oxford University Press.

(1997): "The Decision to Export in Colombia: An Empirical Model of Entry with Sunk Costs," American Economic Review, 87, 545-564.

Romer, P. M. (1990): "Endogenous Technological Change," Journal of Political Economy, Vol. 98, No. 5, pp. S71-S102.

Sampson, T. (forthcoming): "Dynamic Selection: An Idea Flows Theory of Entry, Trade and Growth," Quarterly Journal of Economics.

Vogel, A. And J. Wagner (2010): "Higher productivity in importing German manufacturing firms: self-selection, learning from importing, or both?" Review of World Economics, vol. $145(4)$, pp. 641-665. 


\section{Appendices}

\section{A Algorithm to Evaluate $V^{1}\left(s_{j t}\right)$ and $V^{0}\left(s_{j t}\right)$}

Given all parameters in the production function, productivity evolution process, and demand elasticity, we are going to estimate the parameters governing the distribution of fixed and sunk costs in the dynamic model. This appendix summarizes the algorithm.

1. Pick a starting parameter $\left(\lambda_{s}^{0}, \lambda_{f}^{0}\right) \in \Lambda$.

2. Discretize the state space $\bar{S}$ into $S$. I choose 25 grids for productivity and capital, respectively. Then the total number of grids is $N=2 * 25 * 25=1250$ due to the discrete importing status in the state.

3. Given $\left(\lambda_{s}^{0}, \lambda_{f}^{0}\right)$, solve firms' dynamic importing problem and compute the value function $V\left(s \mid \lambda_{s}^{0}, \lambda_{f}^{0}\right)$ defined in equation (7), for each discretized state in $s \in S$.

The algorithm to compute $V\left(S \mid \lambda_{s}^{0}, \lambda_{f}^{0}\right)$ is as follows:

3.1: Pick a starting value function $V_{0}(S)$.

3.2: Compute the choice-specific value function $V^{1}(S)$ and $V^{0}(S)$ from equations (8), and (9), where $F\left(w_{j t+1} \mid \omega_{j t}, d_{j t}\right)$ is derived from the productivity evolution process, and $\gamma_{j t}$ is assumed to be constant over time for simplicity since the panel is short. The integration is taken using numerical methods (quadrature).

3.3: Use $\pi(S), V^{1}(S)$ and $V^{0}(S)$ to update the value function to $V_{1}(S)$ using Eq. (7). Given the exponential distribution of sunk and fixed costs of importing, I can integrate out the fixed and sunk costs as a closed-form solution.

\section{4: if $\left|V_{1}(S)-V_{0}(S)\right| \geq 10^{-6}$, go back to step 3.2 .}

Iterate until $\left|V_{i+1}(S)-V_{i}(S)\right|$ is small enough, so that $V_{i}(S)$ converges to firm value $V(S)$. This finishes computing the value function in the discretized state space $S$. Note that all the values on the grid points are solved out point by point.

4. We then use cubic spline to construct the value for each data point given parameter $\left(\lambda_{s}^{0}, \lambda_{f}^{0}\right)$, $V\left(\right.$ data $\left.\mid \lambda_{s}^{0}, \lambda_{f}^{0}\right)$. With the value function and the assumption on the distribution of $C_{j t}^{f}$ and $C_{j t}^{s}$ in hand, we can write down the likelihood functions for the data sample as a function of the observed data and $\left(\lambda_{s}^{0}, \lambda_{f}^{0}\right): L\left(\right.$ data $\left.\mid \lambda_{s}^{0}, \lambda_{f}^{0}\right)$.

5. Search over all the points in the parameter space $\Lambda$ (or use other optimization algorithms). Pick $\left(\lambda_{s}, \lambda_{f}\right)^{*}=\arg \max _{\left(\lambda_{s}, \lambda_{f}\right) \in \Lambda} L\left(\right.$ data $\left.\mid \lambda_{s}^{0}, \lambda_{f}^{0}\right)$ as the estimates of the dynamic parameters.

The firm's importing policy function, firm value $\left(V(S)\right.$ in this appendix, or $V\left(s_{j t}\right)$ in Eq. 7$)$, and choice-specific firm value $\left(V^{1}(S)\right.$ and $V^{0}(S)$ in this appendix, or $V^{1}\left(s_{j t}\right)$ and $V^{0}\left(s_{j t}\right)$ in Eq. 7$)$ are all estimated simultaneously in the estimation process. 
Table 1: summary statistics of major variables ${ }^{1}$

\begin{tabular}{|c|c|c|c|c|c|}
\hline Industry & $\begin{array}{l}\text { sample } \\
\text { size }\end{array}$ & $\begin{array}{l}\text { import } \\
\% \text { obs. }\end{array}$ & $\begin{array}{l}\text { import } \\
\% \text { value }\end{array}$ & $\begin{array}{c}\text { mean } \\
\text { mat_dom }\end{array}$ & $\begin{array}{c}\text { cond. mean } \\
\text { mat_imp }\end{array}$ \\
\hline pharmaceuticals & 1793 & .7156 & .6282 & $\begin{array}{c}16.1295 \\
(29.7772)\end{array}$ & $\begin{array}{c}38.0794 \\
(67.4765)\end{array}$ \\
\hline printing and publishing & 5355 & .2409 & .3616 & $\begin{array}{c}8.2753 \\
(39.6131)\end{array}$ & $\begin{array}{l}19.4701 \\
(61.9517)\end{array}$ \\
\hline structural metal products & 2373 & .2137 & .2795 & $\begin{array}{c}5.7449 \\
(10.8392)\end{array}$ & $\begin{array}{c}10.4289 \\
(38.6984)\end{array}$ \\
\hline other metal products & 2643 & .3806 & .3001 & $\begin{array}{l}17.3018 \\
(38.8004)\end{array}$ & $\begin{array}{l}19.4869 \\
(37.5404)\end{array}$ \\
\hline all industries & 12164 & .3359 & .4271 & $\begin{array}{c}10.9009 \\
(34.5315)\end{array}$ & $\begin{array}{c}24.1968 \\
(57.1717)\end{array}$ \\
\hline Industry & $\begin{array}{l}\text { cond. mean } \\
\text { mat_dom }\end{array}$ & $\begin{array}{c}\text { mean } \\
\text { capital }\end{array}$ & $\begin{array}{c}\text { mean } \\
\text { workers }\end{array}$ & $\begin{array}{c}\text { mean } \\
\text { investment }\end{array}$ & $\begin{array}{c}\text { mean } \\
\text { revenue }\end{array}$ \\
\hline pharmaceuticals & $\begin{array}{c}20.9560 \\
(33.6559)\end{array}$ & $\begin{array}{c}11.6699 \\
(24.2421)\end{array}$ & $\begin{array}{c}101.0907 \\
(125.8369)\end{array}$ & $\begin{array}{c}2.7696 \\
(9.5916)\end{array}$ & $\begin{array}{c}98.7252 \\
(169.8494)\end{array}$ \\
\hline printing and publishing & $\begin{array}{l}22.90628 \\
(77.4560)\end{array}$ & $\begin{array}{c}7.8736 \\
(33.2278)\end{array}$ & $\begin{array}{c}57.2537 \\
(146.2721)\end{array}$ & $\begin{array}{c}1.9453 \\
(10.9116)\end{array}$ & $\begin{array}{c}29.7446 \\
(126.9475)\end{array}$ \\
\hline structural metal products & $\begin{array}{c}10.6871 \\
(16.7525)\end{array}$ & $\begin{array}{c}3.7963 \\
(19.5289)\end{array}$ & $\begin{array}{c}40.5129 \\
(88.9391)\end{array}$ & $\begin{array}{l}1.10125 \\
(9.2125)\end{array}$ & $\begin{array}{c}17.4987 \\
(57.8258)\end{array}$ \\
\hline other metal products & $\begin{array}{c}30.7325 \\
(54.1518)\end{array}$ & $\begin{array}{c}7.4719 \\
(15.6685)\end{array}$ & $\begin{array}{c}64.2513 \\
(81.7571)\end{array}$ & $\begin{array}{c}1.7866 \\
(6.0336)\end{array}$ & $\begin{array}{c}44.6487 \\
(90.9752)\end{array}$ \\
\hline all industries & $\begin{array}{c}22.7045 \\
(55.1254)\end{array}$ & $\begin{array}{c}7.5517 \\
(26.5677)\end{array}$ & $\begin{array}{c}61.9815 \\
(122.8011)\end{array}$ & $\begin{array}{c}1.8677 \\
(9.5215)\end{array}$ & $\begin{array}{c}40.7628 \\
(120.2148)\end{array}$ \\
\hline
\end{tabular}

${ }^{1}$ All values are calculated in million of 1977 Colombian Peso. Standard deviations, when necessary, are reported in parentheses. Conditional mean of imported material ("cond. mean mat_imp") and conditional mean of domestic material ("cond. mean mat_dom") are calculated as the simple average of expenditure spent on imported material and domestic material, respectively, by plants that import positive amount of material inputs.

Table 2: transition probability of importing status

\begin{tabular}{l|cc|cc}
\hline & \multicolumn{2}{c}{$d_{j t-1}=0$} & \multicolumn{2}{c}{$d_{j t-1}=1$} \\
\hline Industry & $d_{j t}=0$ & $d_{j t}=1$ & $d_{j t}=0$ & $d_{j t}=1$ \\
\hline pharmaceuticals & .9082 & .0918 & .0457 & .9543 \\
printing and publishing & .9642 & .0358 & .1440 & .8560 \\
structural metal products & .9579 & .0421 & .1782 & .8218 \\
other metal products & .9330 & .0670 & .1164 & .8834 \\
all industries & .9527 & .0473 & .1105 & .8895 \\
\hline
\end{tabular}

\footnotetext{
${ }^{1}$ The first observation of each firm in the data was excluded, because we do not observe their lagged importing status before the first observation.
} 
Table 3: labor productivity for importers and non-importers ${ }^{1}$

\begin{tabular}{l|cc|cc}
\hline & \multicolumn{2}{c}{ for importers } & \multicolumn{2}{c}{ for non-importers } \\
\hline Industry & mean & standard variation & mean & standard variation \\
\hline pharmaceuticals & .8235 & .9852 & .3278 & .2642 \\
printing and publishing & .4429 & .4679 & .2451 & .2022 \\
structural metal products & .5251 & .7265 & .3142 & .4821 \\
other metal products & .7116 & .6418 & .3746 & .5834 \\
all industries & .6387 & .7524 & .2924 & .3874 \\
\hline
\end{tabular}

${ }^{1}$ Labor productivity is defined as revenue per worker, in which revenue is in million of 1977 Colombian Peso.

Table 4: estimates of production function parameters

\begin{tabular}{c|cccc}
\hline \multirow{2}{*}{ Industry } & $\begin{array}{c}\text { pharma- } \\
\text { ceuticals }\end{array}$ & $\begin{array}{c}\text { printing and } \\
\text { publishing }\end{array}$ & $\begin{array}{c}\text { structural } \\
\text { metal products }\end{array}$ & $\begin{array}{c}\text { other metal } \\
\text { products }\end{array}$ \\
\hline$\alpha_{\ell}$ & 0.2543 & 0.4360 & 0.3154 & 0.2840 \\
$\alpha_{m}$ & $(0.0456)^{1}$ & $(0.0393)$ & $(0.0289)$ & $(0.0271)$ \\
& 0.6480 & 0.5414 & 0.6032 & 0.6519 \\
$\alpha_{k}$ & $(0.0312)$ & $(0.0274)$ & $(0.0258)$ & $(0.0140)$ \\
\multirow{4}{*}{$A$} & 0.0828 & 0.0650 & 0.0778 & 0.0623 \\
& $(0.0068)$ & $(0.0040)$ & $(0.0062)$ & $(0.0020)$ \\
$\frac{\theta-1}{\theta}$ & 1.0281 & 1.0060 & 1.1606 & 1.1207 \\
& $(0.1780)$ & $(0.1368)$ & $(0.2417)$ & $(0.0794)$ \\
& 0.7491 & 0.7144 & 0.9091 & 0.8888 \\
& $(0.1791)$ & $(0.1160)$ & $(0.2607)$ & $(0.1448)$ \\
\hline
\end{tabular}

${ }^{1}$ Standard errors are reported in parentheses. I will keep this rule throughout the paper unless otherwise specified.

Table 5: estimates of productivity evolution parameters and demand elasticity

\begin{tabular}{|c|c|c|c|c|}
\hline Industry & $\begin{array}{l}\text { pharma- } \\
\text { ceuticals }\end{array}$ & $\begin{array}{l}\text { printing and } \\
\text { publishing }\end{array}$ & $\begin{array}{c}\text { structural } \\
\text { metal products }\end{array}$ & $\begin{array}{c}\text { other metal } \\
\text { products }\end{array}$ \\
\hline & \multicolumn{4}{|c|}{ Panel A: basic model } \\
\hline \multirow[t]{2}{*}{$g_{0}$} & 0.1936 & 0.2042 & 0.4149 & 0.2217 \\
\hline & $(0.0381)$ & $(0.0289)$ & $(0.0632)$ & $(0.0322)$ \\
\hline \multirow[t]{2}{*}{$g_{\omega}$} & 0.9132 & 0.9221 & 0.8223 & 0.9016 \\
\hline & $(0.0178)$ & $(0.0114)$ & $(0.0269)$ & $(0.0147)$ \\
\hline \multirow[t]{2}{*}{$g_{d}$} & 0.0160 & 0.0097 & 0.0589 & 0.0126 \\
\hline & $(0.0054)$ & $(0.0028)$ & $(0.0083)$ & $(0.0032)$ \\
\hline \multirow[t]{2}{*}{$\sigma_{\omega}$} & 0.0636 & 0.0547 & 0.0669 & 0.0484 \\
\hline & \multicolumn{4}{|c|}{ Panel B: control for export } \\
\hline \multirow[t]{2}{*}{$g_{0}$} & 0.3090 & 0.2338 & 0.4221 & 0.2348 \\
\hline & $(0.0453)$ & $(0.0318)$ & $(0.0649)$ & $(0.0335)$ \\
\hline \multirow[t]{2}{*}{$g_{\omega}$} & 0.8676 & 0.9099 & 0.8193 & 0.8960 \\
\hline & $(0.0202)$ & $(0.0127)$ & $(0.0276)$ & $(0.0152)$ \\
\hline \multirow[t]{2}{*}{$g_{d}$} & 0.0109 & 0.0054 & 0.0580 & 0.0127 \\
\hline & $(0.0058)$ & $(0.0021)$ & $(0.0085)$ & $(0.0033)$ \\
\hline \multirow[t]{2}{*}{$g_{e}$} & 0.0229 & 0.0111 & 0.0085 & 0.0037 \\
\hline & $(0.0048)$ & $(0.0040)$ & $(0.0162)$ & $(0.0030)$ \\
\hline$\sigma_{\omega}$ & 0.0712 & 0.0619 & 0.0757 & 0.0534 \\
\hline \multirow{3}{*}{$\eta$} & \multicolumn{4}{|c|}{ Panel C: demand elasticity } \\
\hline & -3.3001 & -2.7001 & -3.7399 & -4.2012 \\
\hline & $(0.0039)$ & $(0.0025)$ & $(0.0130)$ & $(0.0030)$ \\
\hline
\end{tabular}


Table 6: implied revenue function parameters: sources of static gains

\begin{tabular}{c|cccc}
\hline \multirow{2}{*}{ Industry } & $\begin{array}{c}\text { pharma- } \\
\text { ceuticals }\end{array}$ & $\begin{array}{c}\text { printing and } \\
\text { publishing }\end{array}$ & $\begin{array}{c}\text { structural } \\
\text { metal products }\end{array}$ & $\begin{array}{c}\text { other metal } \\
\text { products }\end{array}$ \\
\hline$r_{w}$ & 1.6948 & 1.5999 & 2.0576 & 2.4859 \\
& $(0.0659)^{1}$ & $(0.0657)$ & $(0.0561)$ & $(0.0428)$ \\
$r_{k}$ & 0.1556 & 0.1063 & 0.1744 & 0.1655 \\
& $(0.0082)$ & $(0.0057)$ & $(0.0089)$ & $(0.0095)$ \\
$r_{d}$ & 0.2998 & 0.2482 & 0.2247 & 0.2705 \\
& $(0.0510)$ & $(0.0134)$ & $(0.0618)$ & $(0.0131)$ \\
\hline
\end{tabular}

${ }^{1}$ The standard errors are constructed using 200 simulations based on estimates of production function parameters.

Table 7: distribution of sunk and fixed cost (MLE)

\begin{tabular}{c|cccc}
\hline \multirow{2}{*}{ Industry } & $\begin{array}{c}\text { pharma- } \\
\text { ceuticals }\end{array}$ & $\begin{array}{c}\text { printing and } \\
\text { publishing }\end{array}$ & $\begin{array}{c}\text { structural } \\
\text { metal products }\end{array}$ & $\begin{array}{c}\text { other metal } \\
\text { products }\end{array}$ \\
\hline$\lambda_{s}$ & 12.6312 & 12.1724 & 13.7615 & 12.7460 \\
& $(0.2433)$ & $(0.1482)$ & $(0.2483)$ & $(0.1508)$ \\
$\lambda_{f}$ & 9.3439 & 8.0794 & 9.7302 & 9.5005 \\
& $(0.0376)$ & $(0.0214)$ & $(0.0281)$ & $(0.0250)$ \\
obj.fun & 155.5258 & 430.8441 & 155.2375 & 313.6812 \\
\hline
\end{tabular}

Table 8: total gains from importing (in millions of 1977 Pesos)

\begin{tabular}{l|rrrr}
\hline Industry & $V\left(s_{j t}\right)$ & $V\left(\omega_{j t}, k_{j t}\right)$ & Total Gain & Total Gain $(\%)^{1}$ \\
\hline pharmaceuticals & 844.5119 & 643.6179 & 200.8938 & $23.79 \%$ \\
printing and publishing & 207.7018 & 182.9481 & 24.7537 & $11.92 \%$ \\
structural metal products & 403.6704 & 320.3828 & 83.2876 & $20.63 \%$ \\
other metal products & 599.1136 & 476.9495 & 122.1641 & $20.39 \%$ \\
\hline
\end{tabular}

${ }^{1}$ It is defined as the ratio of total gains divided by original firm value.

Table 9: dynamic and static gains from importing (in millions of 1977 Pesos)

\begin{tabular}{l|rr|rr|r}
\hline & \multicolumn{2}{c}{ Dynamic Effect } & \multicolumn{2}{c}{ Static Effect } & Total Gain \\
\hline Industry & Value & Value $(\%)^{1}$ & Value & Value $(\%)^{1}$ & \\
\hline pharmaceuticals & 50.0646 & $5.93 \%$ & 150.8292 & $17.86 \%$ & 200.8938 \\
printing and publishing & 3.9237 & $1.89 \%$ & 20.8300 & $10.03 \%$ & 24.7537 \\
structural metal products & 74.3358 & $18.41 \%$ & 8.9518 & $2.22 \%$ & 83.2876 \\
other metal products & 54.4141 & $9.08 \%$ & 67.7500 & $11.31 \%$ & 122.1641 \\
\hline
\end{tabular}

\footnotetext{
${ }^{1}$ They are defined as the ratio of gains from each effect to the original firm value.
} 
Table 10: counterfactual import liberalization/protection and firm value - when policy changes both sunk and fixed costs

\begin{tabular}{c|cccc}
\hline Industry & $\begin{array}{c}\text { pharma- } \\
\text { ceuticals }\end{array}$ & $\begin{array}{c}\text { printing and } \\
\text { publishing }\end{array}$ & $\begin{array}{c}\text { structural } \\
\text { metal products }\end{array}$ & $\begin{array}{c}\text { other metal } \\
\text { products }\end{array}$ \\
\hline & Panel A: & & & \\
$-5 \%$ & $0.33 \%$ & $0.35 \%$ & $0.73 \%$ & $0.51 \%$ \\
$-10 \%$ & $0.67 \%$ & $0.72 \%$ & $1.49 \%$ & $1.02 \%$ \\
$-25 \%$ & $1.70 \%$ & $1.95 \%$ & $4.09 \%$ & $2.68 \%$ \\
$-50 \%$ & $3.53 \%$ & $4.56 \%$ & $9.91 \%$ & $5.83 \%$ \\
\hline & Panel B: & & & \\
$+5 \%$ & $-0.33 \%$ & $-0.34 \%$ & $-0.69 \%$ & $-0.49 \%$ \\
$+10 \%$ & $-0.65 \%$ & $-0.66 \%$ & $-1.34 \%$ & $-0.97 \%$ \\
$+25 \%$ & $-1.61 \%$ & $-1.55 \%$ & $-3.13 \%$ & $-2.34 \%$ \\
$+50 \%$ & $-3.14 \%$ & $-2.84 \%$ & $-5.67 \%$ & $-4.42 \%$ \\
\hline
\end{tabular}


Table 11: counterfactual import liberalization/protection and firm value - when policy changes sunk and fixed costs separately

\begin{tabular}{|c|c|c|c|c|}
\hline Industry & $\begin{array}{l}\text { pharma- } \\
\text { ceuticals }\end{array}$ & $\begin{array}{c}\text { printing and } \\
\text { publishing }\end{array}$ & $\begin{array}{c}\text { structural } \\
\text { metal products }\end{array}$ & $\begin{array}{c}\text { other metal } \\
\text { products }\end{array}$ \\
\hline & \multicolumn{4}{|c|}{ Part I: when policy changes fixed cost only } \\
\hline & \multicolumn{4}{|l|}{ Panel A: } \\
\hline$-5 \%$ & $0.26 \%$ & $0.16 \%$ & $0.39 \%$ & $0.33 \%$ \\
\hline$-10 \%$ & $0.52 \%$ & $0.32 \%$ & $0.78 \%$ & $0.66 \%$ \\
\hline$-25 \%$ & $1.30 \%$ & $0.81 \%$ & $1.95 \%$ & $1.65 \%$ \\
\hline \multirow[t]{2}{*}{$-50 \%$} & $2.61 \%$ & $1.63 \%$ & $3.96 \%$ & $3.33 \%$ \\
\hline & \multicolumn{4}{|l|}{ Panel B: } \\
\hline$+5 \%$ & $-0.26 \%$ & $-0.16 \%$ & $-0.39 \%$ & $-0.33 \%$ \\
\hline$+10 \%$ & $-0.52 \%$ & $-0.32 \%$ & $-0.77 \%$ & $-0.65 \%$ \\
\hline$+25 \%$ & $-1.30 \%$ & $-0.79 \%$ & $-1.90 \%$ & $-1.61 \%$ \\
\hline \multirow[t]{3}{*}{$+50 \%$} & $-2.58 \%$ & $-1.57 \%$ & $-3.74 \%$ & $-3.16 \%$ \\
\hline & \multicolumn{4}{|c|}{ Part II: when policy changes sunk cost only } \\
\hline & \multicolumn{4}{|l|}{ Panel A: } \\
\hline$-5 \%$ & $0.07 \%$ & $0.19 \%$ & $0.33 \%$ & $0.18 \%$ \\
\hline$-10 \%$ & $0.15 \%$ & $0.39 \%$ & $0.69 \%$ & $0.36 \%$ \\
\hline$-25 \%$ & $0.39 \%$ & $1.09 \%$ & $1.96 \%$ & $0.97 \%$ \\
\hline \multirow[t]{2}{*}{$-50 \%$} & $0.86 \%$ & $2.67 \%$ & $5.06 \%$ & $2.25 \%$ \\
\hline & \multicolumn{4}{|l|}{ Panel B: } \\
\hline$+5 \%$ & $-0.07 \%$ & $-0.18 \%$ & $-0.31 \%$ & $-0.17 \%$ \\
\hline$+10 \%$ & $-0.13 \%$ & $-0.35 \%$ & $-0.60 \%$ & $-0.33 \%$ \\
\hline$+25 \%$ & $-0.32 \%$ & $-0.80 \%$ & $-1.35 \%$ & $-0.76 \%$ \\
\hline \multirow[t]{3}{*}{$+50 \%$} & $-0.59 \%$ & $-1.41 \%$ & $-2.34 \%$ & $-1.38 \%$ \\
\hline & \multicolumn{4}{|c|}{ Part III: ratio of the effects: fixed to sunk } \\
\hline & \multicolumn{4}{|l|}{ Panel A: } \\
\hline$-5 \%$ & 3.71 & 0.85 & 1.16 & 1.88 \\
\hline$-10 \%$ & 3.47 & 0.82 & 1.12 & 1.82 \\
\hline$-25 \%$ & 3.33 & 0.74 & 1.00 & 1.70 \\
\hline \multirow[t]{2}{*}{$-50 \%$} & 3.03 & 0.61 & 0.78 & 1.48 \\
\hline & \multicolumn{4}{|l|}{ Panel B: } \\
\hline$+5 \%$ & 3.71 & 0.89 & 1.25 & 1.95 \\
\hline$+10 \%$ & 4.00 & 0.92 & 1.29 & 1.99 \\
\hline$+25 \%$ & 4.06 & 0.99 & 1.41 & 2.11 \\
\hline$+50 \%$ & 4.37 & 1.12 & 1.60 & 2.29 \\
\hline
\end{tabular}

${ }^{1}$ The ratio of effects are defined as the ratio of gains from changing fixed costs (in Part I) to that from changing sunk costs (in Part II), given that the sunk and fixed costs are changed by the same percentage in these two separate counterfactual experiments.

Table 12: counterfactual tariff reduction and firm value

\begin{tabular}{c|cccc}
\hline $\begin{array}{c}\text { tariff } \\
\text { reduction }\end{array}$ & $\begin{array}{c}\text { pharma- } \\
\text { ceuticals }\end{array}$ & $\begin{array}{c}\text { printing and } \\
\text { publishing }\end{array}$ & $\begin{array}{c}\text { structural } \\
\text { metal products }\end{array}$ & $\begin{array}{c}\text { other metal } \\
\text { products }\end{array}$ \\
\hline$-5 \%$ & $0.63 \%$ & $0.96 \%$ & $2.81 \%$ & $2.65 \%$ \\
$-10 \%$ & $1.34 \%$ & $2.06 \%$ & $6.20 \%$ & $5.83 \%$ \\
$-15 \%$ & $2.13 \%$ & $3.32 \%$ & $10.23 \%$ & $9.57 \%$ \\
$-17 \%$ & $2.48 \%$ & $3.88 \%$ & $12.04 \%$ & $11.24 \%$ \\
$-20 \%$ & $3.02 \%$ & $4.78 \%$ & $14.98 \%$ & $13.93 \%$ \\
$-25 \%$ & $4.02 \%$ & $6.45 \%$ & $20.52 \%$ & $18.94 \%$ \\
\hline
\end{tabular}


Table A1: estimates of productivity evolution parameters using import expenditure share ${ }^{1}$ (robustness check)

\begin{tabular}{|c|c|c|c|c|}
\hline Industry & $\begin{array}{l}\text { pharma- } \\
\text { ceuticals }\end{array}$ & $\begin{array}{l}\text { printing and } \\
\text { publishing }\end{array}$ & $\begin{array}{c}\text { structural } \\
\text { metal products }\end{array}$ & $\begin{array}{l}\text { other metal } \\
\text { products }\end{array}$ \\
\hline & \multicolumn{4}{|c|}{ Panel A: basic model ${ }^{2}$} \\
\hline \multirow[t]{2}{*}{$g_{0}$} & 0.2442 & 0.2065 & 0.3167 & 0.1835 \\
\hline & $(0.0458)$ & $(0.0318)$ & $(0.0585)$ & $(0.0285)$ \\
\hline \multirow[t]{2}{*}{$g_{\omega}$} & 0.8946 & 0.9213 & 0.8648 & 0.9186 \\
\hline & $(0.0202)$ & $(0.0127)$ & $(0.0249)$ & $(0.0132)$ \\
\hline \multirow[t]{2}{*}{$g_{d}$} & 0.0300 & 0.0123 & 0.0751 & 0.0111 \\
\hline & $(0.0096)$ & $(0.0045)$ & $(0.0161)$ & $(0.0042)$ \\
\hline \multirow[t]{2}{*}{$\sigma_{\omega}$} & 0.0635 & 0.0547 & 0.0682 & 0.0492 \\
\hline & \multicolumn{4}{|c|}{ Panel B: control for export } \\
\hline \multirow[t]{2}{*}{$g_{0}$} & 0.3069 & 0.2235 & 0.3263 & 0.2060 \\
\hline & $(0.0454)$ & $(0.0320)$ & $(0.0596)$ & $(0.0313)$ \\
\hline \multirow[t]{2}{*}{$g_{\omega}$} & 0.8706 & 0.9154 & 0.8608 & 0.9089 \\
\hline & $(0.0197)$ & $(0.0126)$ & $(0.0254)$ & $(0.0143)$ \\
\hline \multirow[t]{2}{*}{$g_{d}$} & 0.0143 & 0.0132 & 0.0705 & 0.0106 \\
\hline & $(0.0096)$ & $(0.0048)$ & $(0.0173)$ & $(0.0041)$ \\
\hline \multirow[t]{2}{*}{$g_{e}$} & 0.0213 & 0.0139 & 0.0158 & 0.0054 \\
\hline & $(0.0051)$ & $(0.0035)$ & $(0.0181)$ & $(0.0030)$ \\
\hline$\sigma_{\omega}$ & 0.0720 & 0.0613 & 0.0728 & 0.0527 \\
\hline
\end{tabular}

1 As a robustness check, in this table the import expenditure share is used to capture the productivity effect of importing in the productivity evolution process. A positive and significant effect of importing on productivity is also found, as that in Table 5 when importing dummy is used.

2 Panel A: baseline model, $\omega_{j t}=g_{0}+g_{\omega} \omega_{j t-1}+g_{d} s h d_{j t-1}+\xi_{j t}$. Panel B: extended model controlling for export, $\omega_{j t}=g_{0}+g_{\omega} \omega_{j t-1}+$ $g_{d} s h d_{j t-1}+g_{e} e_{j t-1}+\xi_{j t}$. Here $s h d_{j t-1}$ is the expenditure share of imported intermediate inputs in total expenditure on intermediate inputs. 
Table A2: estimates of model parameters for a subsample of non-exporters (robustness check)

\begin{tabular}{|c|c|c|c|c|}
\hline Industry & $\begin{array}{l}\text { pharma- } \\
\text { ceuticals }\end{array}$ & $\begin{array}{c}\text { printing and } \\
\text { publishing }\end{array}$ & $\begin{array}{c}\text { structural } \\
\text { metal products }\end{array}$ & $\begin{array}{c}\text { other metal } \\
\text { products }\end{array}$ \\
\hline & \multicolumn{4}{|c|}{ Panel A: production parameter } \\
\hline \multirow[t]{2}{*}{$\alpha_{\ell}$} & 0.2818 & 0.4491 & 0.2939 & 0.2708 \\
\hline & $(0.0526)$ & $(0.0465)$ & $(0.0337)$ & $(0.0331)$ \\
\hline \multirow[t]{2}{*}{$\alpha_{m}$} & 0.6390 & 0.5353 & 0.6294 & 0.6503 \\
\hline & $(0.0256)$ & $(0.0292)$ & $(0.0182)$ & $(0.0164)$ \\
\hline \multirow[t]{2}{*}{$\alpha_{k}$} & 0.0791 & 0.0478 & 0.0754 & 0.0608 \\
\hline & $(0.0086)$ & $(0.0056)$ & $(0.0050)$ & $(0.0077)$ \\
\hline \multirow[t]{2}{*}{$A$} & 1.1425 & 1.0968 & 1.2397 & 1.1709 \\
\hline & $(0.1833)$ & $(0.1829)$ & $(0.3043)$ & $(0.1132)$ \\
\hline \multirow{3}{*}{$\frac{\theta-1}{\theta}$} & 0.9608 & 0.7878 & 0.9705 & 0.9260 \\
\hline & $(0.3579)$ & $(0.1747)$ & $(0.3363)$ & $(0.1803)$ \\
\hline & \multicolumn{4}{|c|}{ Panel B: productivity evolution } \\
\hline \multirow[t]{2}{*}{$g_{0}$} & 0.4084 & 0.3804 & 0.2973 & 0.2008 \\
\hline & $(0.0848)$ & $(0.0377)$ & $(0.0542)$ & $(0.0460)$ \\
\hline \multirow[t]{2}{*}{$g_{\omega}$} & 0.8207 & 0.8588 & 0.8638 & 0.9133 \\
\hline & $(0.0378)$ & $(0.0148)$ & $(0.0244)$ & $(0.0199)$ \\
\hline \multirow{2}{*}{$g_{d}$} & 0.0411 & 0.0134 & 0.0458 & 0.0086 \\
\hline & $(0.0069)$ & $(0.0047)$ & $(0.0072)$ & $(0.0039)$ \\
\hline \multirow[t]{2}{*}{$\sigma_{\omega}$} & 0.0756 & 0.0632 & 0.0509 & 0.0565 \\
\hline & \multicolumn{4}{|c|}{ Panel C: demand elasticity } \\
\hline \multirow[t]{3}{*}{$\eta$} & -3.0490 & -2.1601 & -3.3156 & -5.3632 \\
\hline & $(0.0053)$ & $(0.0022)$ & $(0.0052)$ & $(0.0039)$ \\
\hline & \multicolumn{4}{|c|}{ Panel D: implied revenue parameter } \\
\hline \multirow[t]{2}{*}{$r_{w}$} & 1.6232 & 1.1217 & 1.8156 & 2.9902 \\
\hline & $(0.0623)^{1}$ & $(0.0629)$ & $(0.0473)$ & $(0.0632)$ \\
\hline \multirow[t]{2}{*}{$r_{k}$} & 0.1413 & 0.0537 & 0.1503 & 0.2080 \\
\hline & $(0.0133)$ & $(0.0068)$ & $(0.0062)$ & $(0.0133)$ \\
\hline \multirow[t]{2}{*}{$r_{d}$} & 0.1518 & 0.1444 & 0.2658 & 0.3550 \\
\hline & $(0.1062)$ & $(0.0222)$ & $(0.2257)$ & $(0.0354)$ \\
\hline \multirow{3}{*}{$\lambda_{s}$} & \multicolumn{4}{|c|}{ Panel E: distribution of fixed/sunk costs } \\
\hline & 11.7420 & 11.2287 & 13.1125 & 12.8337 \\
\hline & $(0.2398)$ & $(0.1827)$ & $(0.2513)$ & $(0.1802)$ \\
\hline \multirow[t]{2}{*}{$\lambda_{f}$} & 8.6417 & 7.0195 & 9.1759 & 9.7160 \\
\hline & $(0.0338)$ & $(0.0218)$ & $(0.0329)$ & $(0.0367)$ \\
\hline obj.fun & 143.3992 & 355.6616 & 143.1515 & 247.0329 \\
\hline
\end{tabular}


Table A3: estimates of static parameters without controlling for age and ownership in $\phi(\cdot)$ (robustness check)

\begin{tabular}{|c|c|c|c|c|}
\hline Industry & $\begin{array}{l}\text { pharma- } \\
\text { ceuticals }\end{array}$ & $\begin{array}{l}\text { printing and } \\
\text { publishing }\end{array}$ & $\begin{array}{c}\text { structural } \\
\text { metal products }\end{array}$ & $\begin{array}{c}\text { other metal } \\
\text { products }\end{array}$ \\
\hline & \multicolumn{4}{|c|}{ Panel A: production parameter } \\
\hline \multirow[t]{2}{*}{$\alpha_{\ell}$} & 0.2691 & 0.4585 & 0.2820 & 0.3001 \\
\hline & $(0.0413)$ & $(0.0337)$ & $(0.0299)$ & $(0.0238)$ \\
\hline \multirow[t]{2}{*}{$\alpha_{m}$} & 0.6588 & 0.5227 & 0.6358 & 0.6580 \\
\hline & $(0.0295)$ & $(0.0263)$ & $(0.0266)$ & $(0.0137)$ \\
\hline \multirow[t]{2}{*}{$\alpha_{k}$} & 0.0791 & 0.0478 & 0.0754 & 0.0608 \\
\hline & $(0.0086)$ & $(0.0056)$ & $(0.0050)$ & $(0.0077)$ \\
\hline \multirow[t]{2}{*}{$A$} & 1.0324 & 1.0093 & 0.9905 & 1.0605 \\
\hline & $(0.1665)$ & $(0.1303)$ & $(0.2203)$ & $(0.0829)$ \\
\hline \multirow{3}{*}{$\frac{\theta-1}{\theta}$} & 0.7672 & 0.7642 & 0.6891 & 0.8394 \\
\hline & $(0.0860)$ & $(0.0668)$ & $(0.0907)$ & $(0.1341)$ \\
\hline & \multicolumn{4}{|c|}{ Panel B: productivity evolution } \\
\hline \multirow[t]{2}{*}{$g_{0}$} & 0.3294 & 0.3975 & 0.5552 & 0.4043 \\
\hline & $(0.0684)$ & $(0.0428)$ & $(0.0668)$ & $(0.0549)$ \\
\hline \multirow[t]{2}{*}{$g_{\omega}$} & 0.8456 & 0.8500 & 0.7346 & 0.8119 \\
\hline & $(0.0335)$ & $(0.0169)$ & $(0.0302)$ & $(0.0275)$ \\
\hline \multirow[t]{2}{*}{$g_{d}$} & 0.0138 & 0.0137 & 0.0153 & 0.0125 \\
\hline & $(0.0043)$ & $(0.0033)$ & $(0.0050)$ & $(0.0028)$ \\
\hline \multirow[t]{2}{*}{$g_{e}$} & 0.0150 & 0.0126 & 0.0104 & 0.0059 \\
\hline & $(0.0040)$ & $(0.0039)$ & $(0.0110)$ & $(0.0030)$ \\
\hline \multirow[t]{2}{*}{$\sigma_{\omega}$} & 0.0674 & 0.0659 & 0.0754 & 0.0519 \\
\hline & \multicolumn{4}{|c|}{ Panel C: demand elasticity } \\
\hline \multirow[t]{3}{*}{$\eta$} & -3.1036 & -2.6821 & -3.7478 & -3.9106 \\
\hline & $(0.0039)$ & $(0.0025)$ & $(0.0130)$ & $(0.0030)$ \\
\hline & \multicolumn{4}{|c|}{ Panel D: implied revenue parameter } \\
\hline \multirow[t]{2}{*}{$r_{w}$} & 1.6948 & 1.5998 & 2.0576 & 2.4859 \\
\hline & $(0.0593)^{1}$ & $(0.0574)$ & $(0.0451)$ & $(0.0380)$ \\
\hline \multirow[t]{2}{*}{$r_{k}$} & 0.1689 & 0.1103 & 0.1986 & 0.1589 \\
\hline & $(0.0089)$ & $(0.0056)$ & $(0.0076)$ & $(0.0075)$ \\
\hline \multirow[t]{2}{*}{$r_{d}$} & 0.2728 & 0.1862 & 0.2338 & 0.2804 \\
\hline & $(0.0084)$ & $(0.0046)$ & $(0.0166)$ & $(0.0106)$ \\
\hline
\end{tabular}


Table A4: Sensitivity of Predicted Gains from Importing to Revenue Intercept Time Dummy

\begin{tabular}{l|lrrr}
\hline Industry & gains & main results & $\max$ & $\min ^{1}$ \\
\hline pharmaceuticals & total & $23.79 \%$ & $24.45 \%$ & $22.44 \%$ \\
& static & $17.86 \%$ & $18.53 \%$ & $16.50 \%$ \\
& dynamic & $5.93 \%$ & $5.92 \%$ & $5.94 \%$ \\
\hline printing and publishing & total & $11.29 \%$ & $12.52 \%$ & $11.16 \%$ \\
& static & $10.03 \%$ & $10.58 \%$ & $9.34 \%$ \\
& dynamic & $1.89 \%$ & $1.94 \%$ & $1.83 \%$ \\
\hline \multirow{2}{*}{ structural metal products } & total & $20.63 \%$ & $23.05 \%$ & $17.24 \%$ \\
& static & $2.22 \%$ & $3.05 \%$ & $1.31 \%$ \\
& dynamic & $18.41 \%$ & $19.99 \%$ & $15.93 \%$ \\
\hline \multirow{2}{*}{ other metal products } & total & $20.39 \%$ & $21.52 \%$ & $18.58 \%$ \\
& static & $11.31 \%$ & $12.28 \%$ & $9.77 \%$ \\
& dynamic & $9.08 \%$ & $9.23 \%$ & $8.80 \%$ \\
\hline
\end{tabular}

${ }^{1}$ The last two columns, respectively, report the model predicted gains from import when the time dummy (i.e. the intercept of revenue function) equals the upper bound and lower bound of the estimates of time dummies.

Table A5: Sensitivity of Predicted Gains from Sunk and Fixed Costs Reduction to Revenue Intercept Time Dummy

\begin{tabular}{|c|c|c|c|c|c|c|c|c|}
\hline \multirow[t]{2}{*}{ Industry } & \multicolumn{2}{|c|}{$\begin{array}{l}\text { pharma- } \\
\text { ceuticals }\end{array}$} & \multicolumn{2}{|c|}{$\begin{array}{l}\text { printing and } \\
\text { publishing }\end{array}$} & \multicolumn{2}{|c|}{$\begin{array}{c}\text { structural } \\
\text { metal products }\end{array}$} & \multicolumn{2}{|c|}{$\begin{array}{l}\text { other metal } \\
\text { products }\end{array}$} \\
\hline & $\frac{\text { Panel A: }}{\max ^{1}}$ & $\min$ & $\max$ & $\min$ & $\max$ & $\min$ & $\max$ & $\min$ \\
\hline$-5 \%$ & $0.30 \%$ & $0.41 \%$ & $0.35 \%$ & $0.36 \%$ & $0.71 \%$ & $0.75 \%$ & $0.46 \%$ & $0.57 \%$ \\
\hline$-10 \%$ & $0.59 \%$ & $0.82 \%$ & $0.71 \%$ & $0.74 \%$ & $1.46 \%$ & $1.54 \%$ & $0.94 \%$ & $1.15 \%$ \\
\hline$-25 \%$ & $1.51 \%$ & $2.08 \%$ & $1.91 \%$ & $2.00 \%$ & $4.00 \%$ & $4.21 \%$ & $2.45 \%$ & $3.03 \%$ \\
\hline$-50 \%$ & $3.13 \%$ & $4.33 \%$ & $4.45 \%$ & $4.69 \%$ & $9.61 \%$ & $10.24 \%$ & $5.31 \%$ & $6.64 \%$ \\
\hline & $\frac{\text { Panel B: }}{\max }$ & $\min$ & $\max$ & $\min$ & $\max$ & $\min$ & $\max$ & $\min$ \\
\hline$+5 \%$ & $-0.29 \%$ & $-0.40 \%$ & $-0.33 \%$ & $-0.34 \%$ & $-0.67 \%$ & $-0.71 \%$ & $-0.45 \%$ & $-0.55 \%$ \\
\hline$+10 \%$ & $-0.58 \%$ & $-0.80 \%$ & $-0.65 \%$ & $-0.67 \%$ & $-1.32 \%$ & $-1.38 \%$ & $-0.89 \%$ & $-1.09 \%$ \\
\hline$+25 \%$ & $-1.43 \%$ & $-1.96 \%$ & $-1.53 \%$ & $-1.58 \%$ & $-3.07 \%$ & $-3.23 \%$ & $-2.16 \%$ & $-2.61 \%$ \\
\hline$+50 \%$ & $-2.80 \%$ & $-3.82 \%$ & $-2.80 \%$ & $-2.89 \%$ & $-5.56 \%$ & $-5.84 \%$ & $-4.09 \%$ & $-4.90 \%$ \\
\hline
\end{tabular}

${ }^{1}$ The "max" columns reports the policy effects when the intercept of revenue function is chosen to be the maximum of the time dummies among all years. The "min" columns reports the policy effects when the intercept of revenue function is chosen to be the maximum of the time dummies among all years.

Table A6: Sensitivity of Predicted Gains from Tariff Reduction to Revenue Intercept Time Dummy

\begin{tabular}{c|cc|cc|cc|cc}
\hline \multirow{2}{*}{$\begin{array}{c}\text { Industry } \\
\end{array}$} & \multicolumn{2}{|c}{$\begin{array}{c}\text { pharma- } \\
\text { ceuticals }\end{array}$} & \multicolumn{2}{c}{$\begin{array}{c}\text { printing and } \\
\text { publishing }\end{array}$} & \multicolumn{2}{c}{$\begin{array}{c}\text { structural } \\
\text { metal products }\end{array}$} & \multicolumn{2}{c}{$\begin{array}{c}\text { other metal } \\
\text { products }\end{array}$} \\
\hline & $\max$ & $\min$ & $\max$ & $\min$ & $\max$ & $\min$ & $\max$ & $\min$ \\
$-5 \%$ & $0.75 \%$ & $0.68 \%$ & $1.04 \%$ & $0.85 \%$ & $3.16 \%$ & $2.33 \%$ & $2.79 \%$ & $2.49 \%$ \\
$-10 \%$ & $1.57 \%$ & $1.45 \%$ & $2.23 \%$ & $1.82 \%$ & $6.93 \%$ & $5.17 \%$ & $6.12 \%$ & $5.52 \%$ \\
$-15 \%$ & $2.50 \%$ & $2.31 \%$ & $3.59 \%$ & $2.95 \%$ & $11.39 \%$ & $8.60 \%$ & $10.02 \%$ & $9.12 \%$ \\
$-17 \%$ & $2.91 \%$ & $2.68 \%$ & $4.20 \%$ & $3.45 \%$ & $13.38 \%$ & $10.15 \%$ & $11.75 \%$ & $10.73 \%$ \\
$-20 \%$ & $3.54 \%$ & $3.28 \%$ & $5.21 \%$ & $4.25 \%$ & $16.59 \%$ & $12.68 \%$ & $14.54 \%$ & $13.33 \%$ \\
$-25 \%$ & $4.72 \%$ & $4.37 \%$ & $7.10 \%$ & $5.77 \%$ & $22.63 \%$ & $17.50 \%$ & $19.73 \%$ & $18.22 \%$ \\
\hline
\end{tabular}


Figure 1: labor productivity and importing history

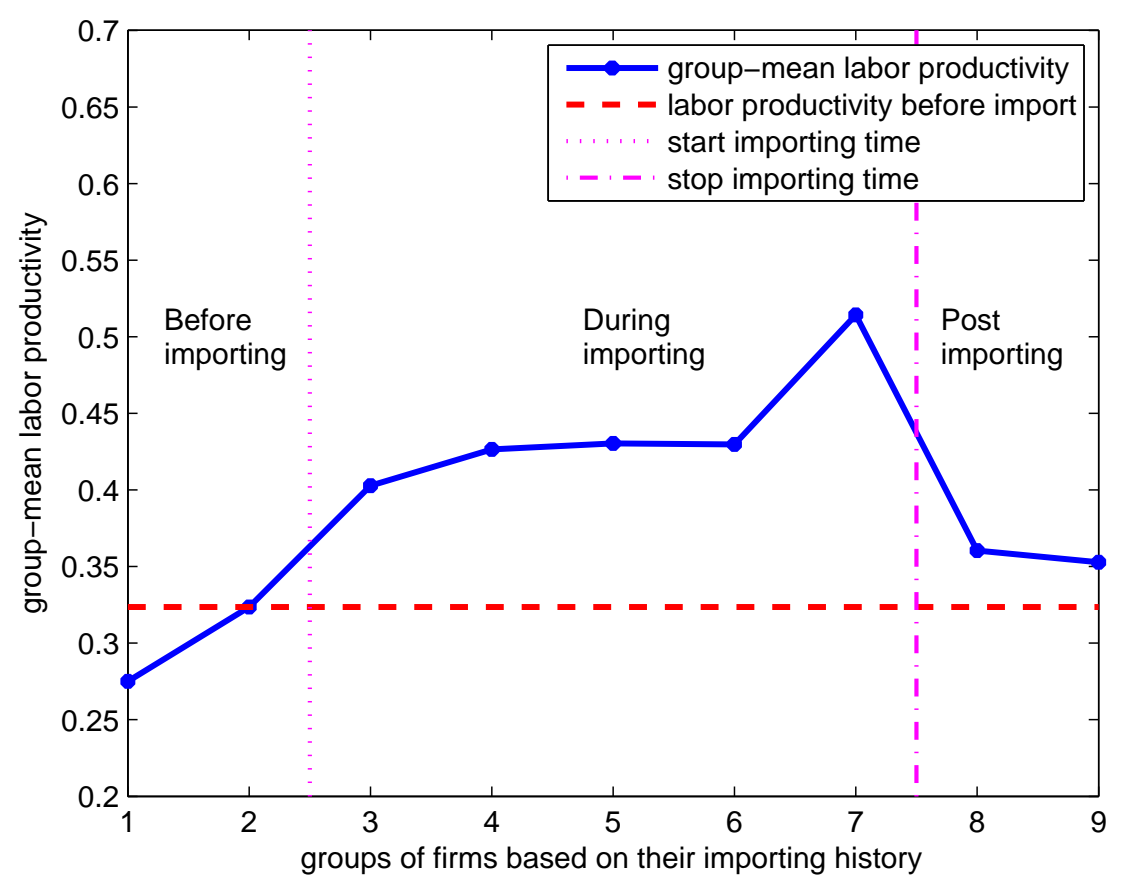

Note: This figure shows the mean of labor productivity, defined as the mean of revenue per worker, for different groups of observations. The groups are defined as follows:

group 1: observations of firms that never import in the data;

group 2: observations just one year before the firm starts importing; group 3: observations of first-year importing; group 4-6: observations of 2nd-4th year of importing, respectively;

group 7: observations that were importing for $N \geq 5$ years;

group 8: observations of the first year after the firm quits importing; group 9: observations of $N \geq 2$ years after the firm quits importing. 
Figure 2: Importing and simulated expected productivity for 30 years
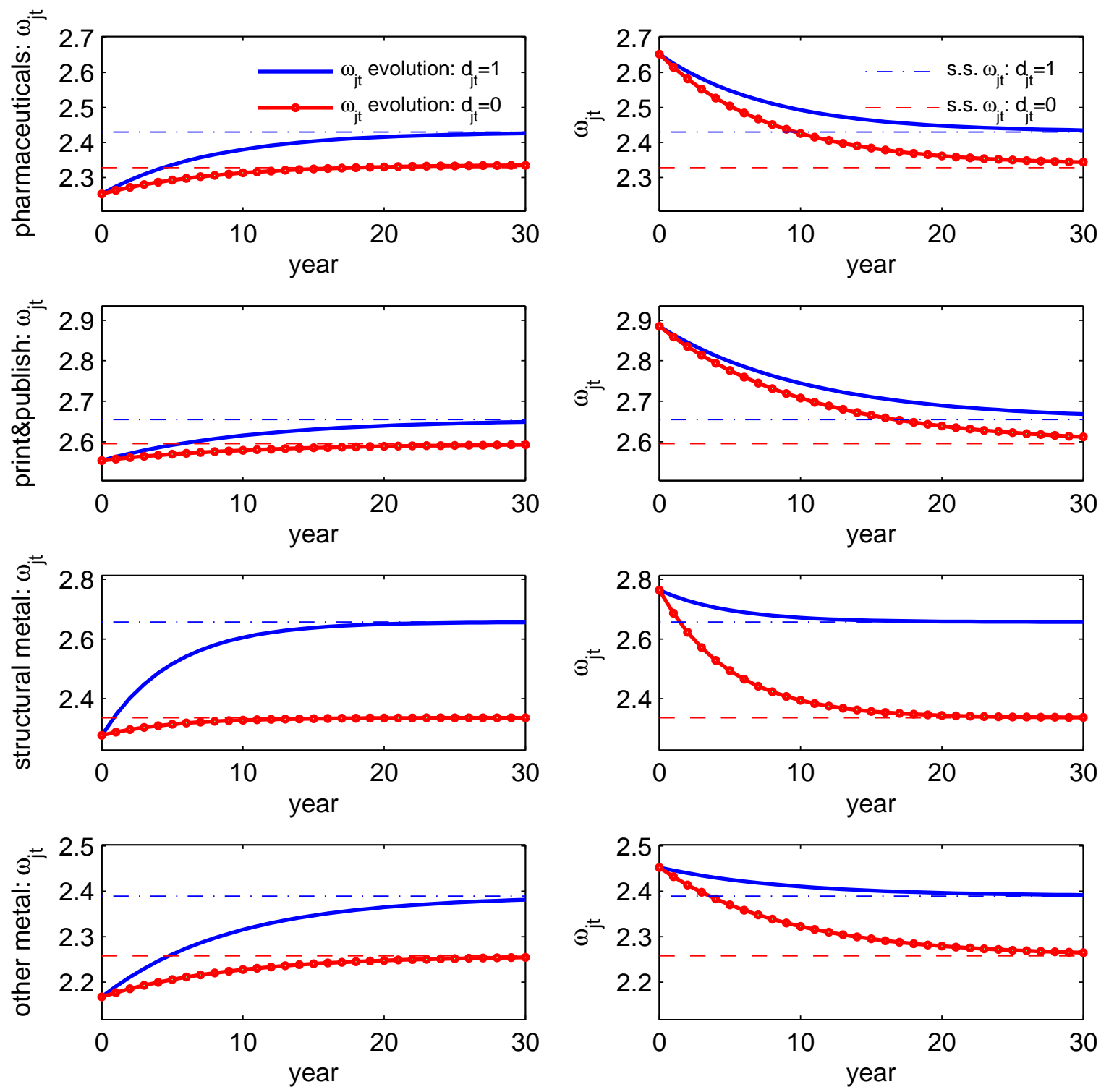

Note: This table simulates the expected productivity for 30 years, for firms that always import and that never. The rows corresponds to the four industries. The columns correspond to different starting productivity, with the left starting from the $10 \%$-quintile productivity of that industry and the right column starting from the $90 \%$-quintile. This figure suggests importing not only improves the productivity growth rate during the transition process, but also increases the steady-state productivity level. 
Figure 3: productivity, costs, and importing decision

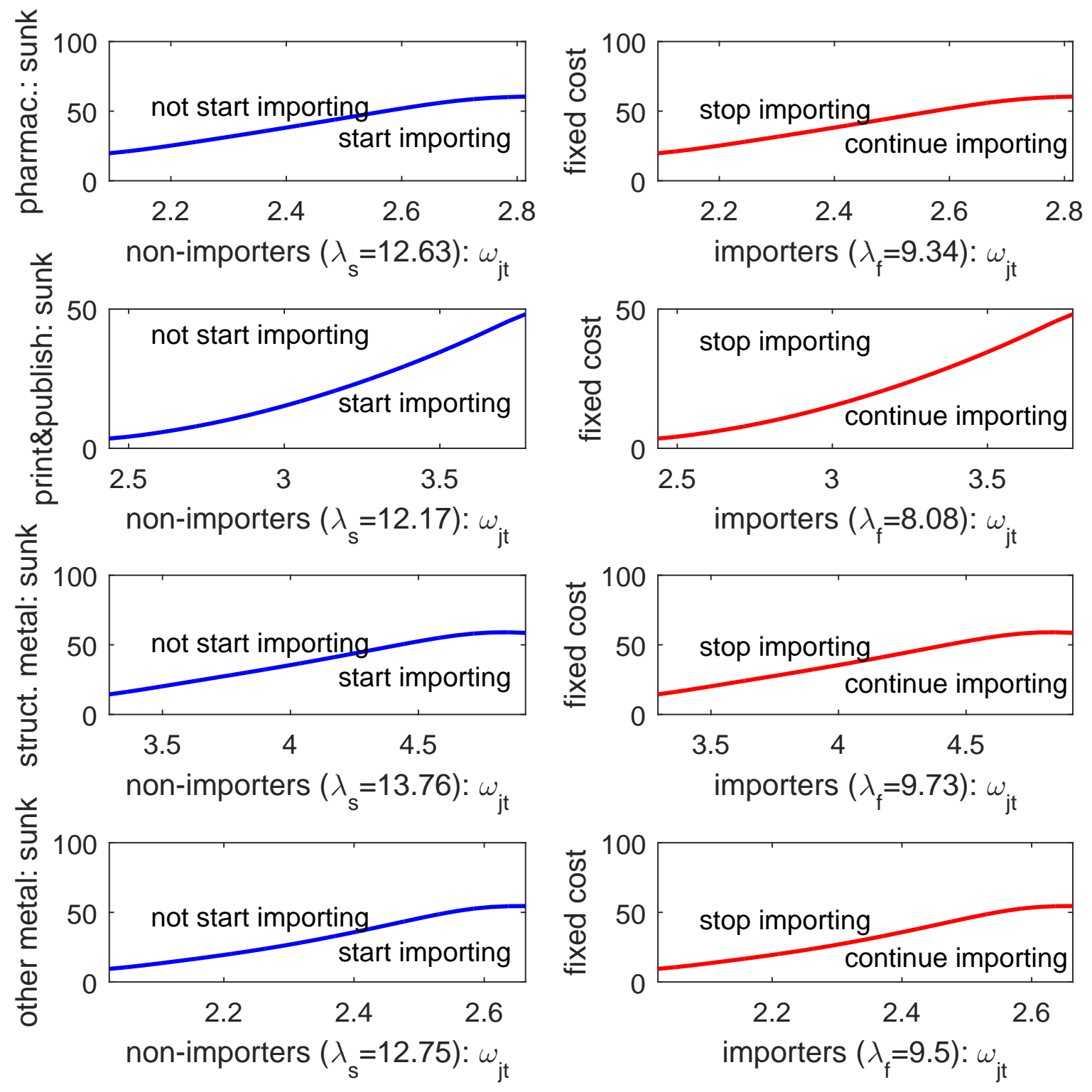

Note: the sunk and fixed costs are calculated in million of 1977 Colombia Peso. The left column referents the importing decisions for firms which did not import and the right column refers to that for firms which were already importing. They correspond to equations (20) and (21), respectively. 
Figure 4: Distribution of firm value in the data, in autarky, and in the case without dynamic gains (firm value in million 1977 Colombia Peso)
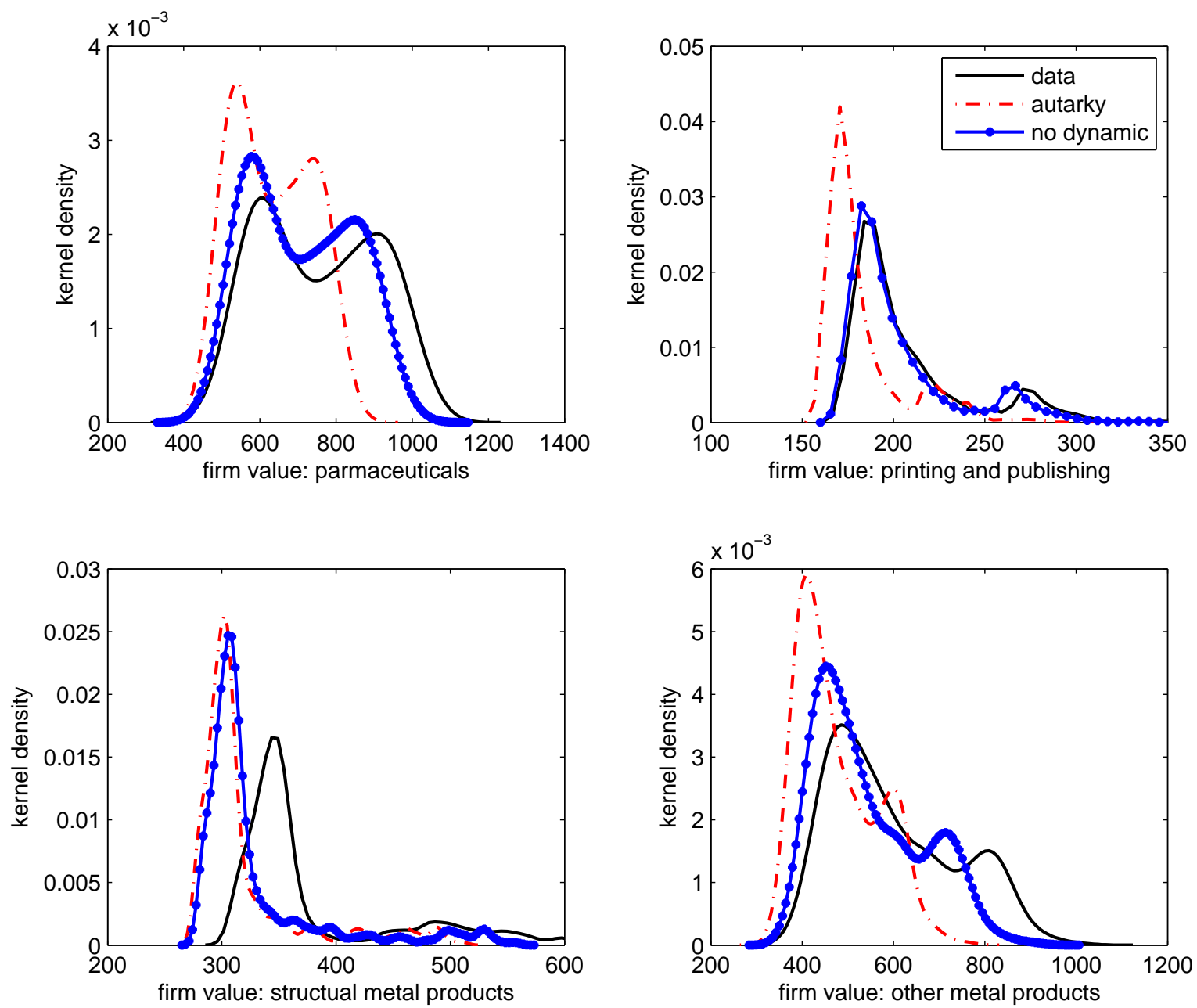
Figure 5: Distribution of firm value when increasing sunk/fixed costs by $25 \%$ and $50 \%$ (firm value in million 1977 Colombia Peso)
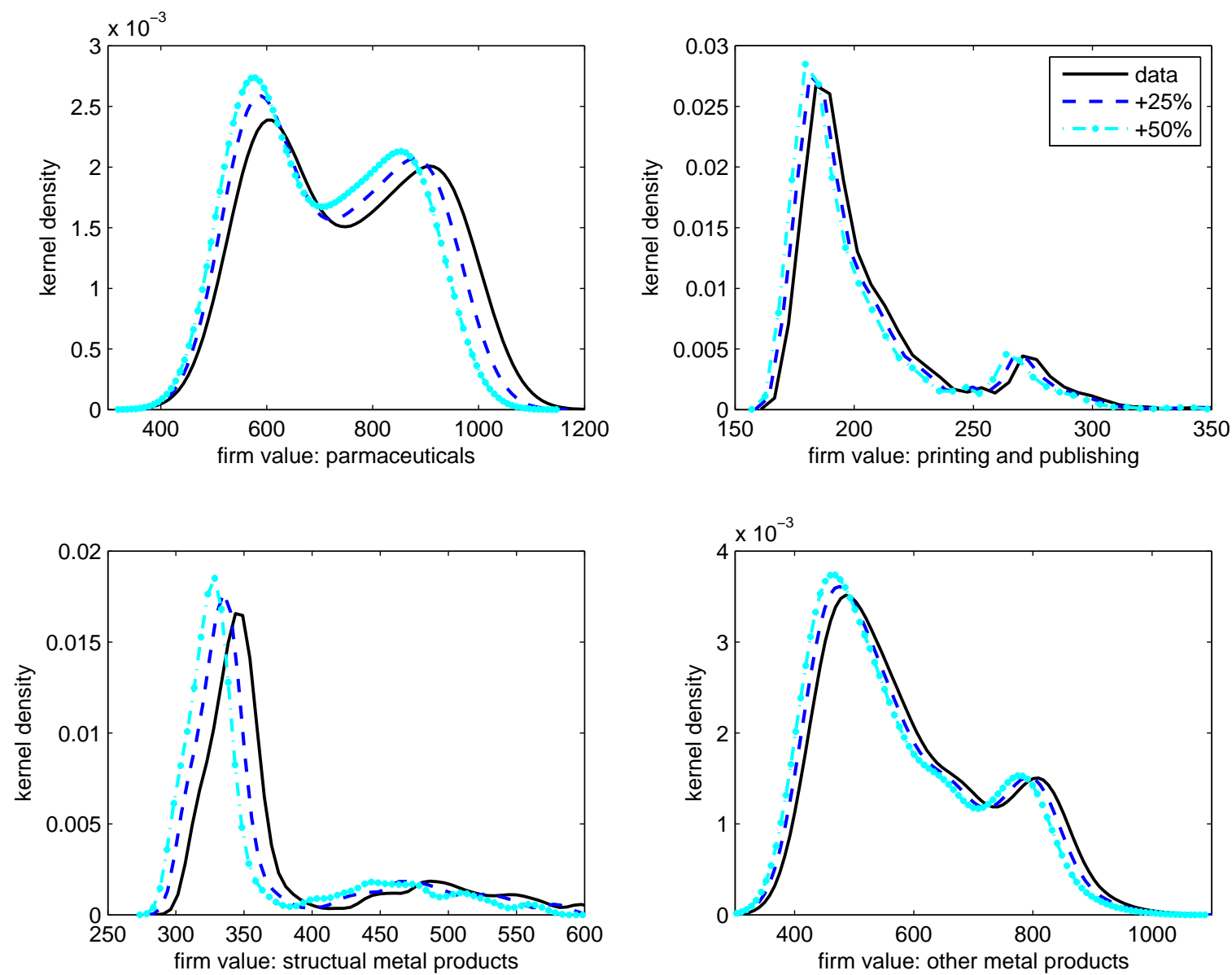
Figure 6: Distribution of firm value when decreasing sunk/fixed costs by $25 \%$ and $50 \%$ (firm value in million 1977 Colombia Peso)
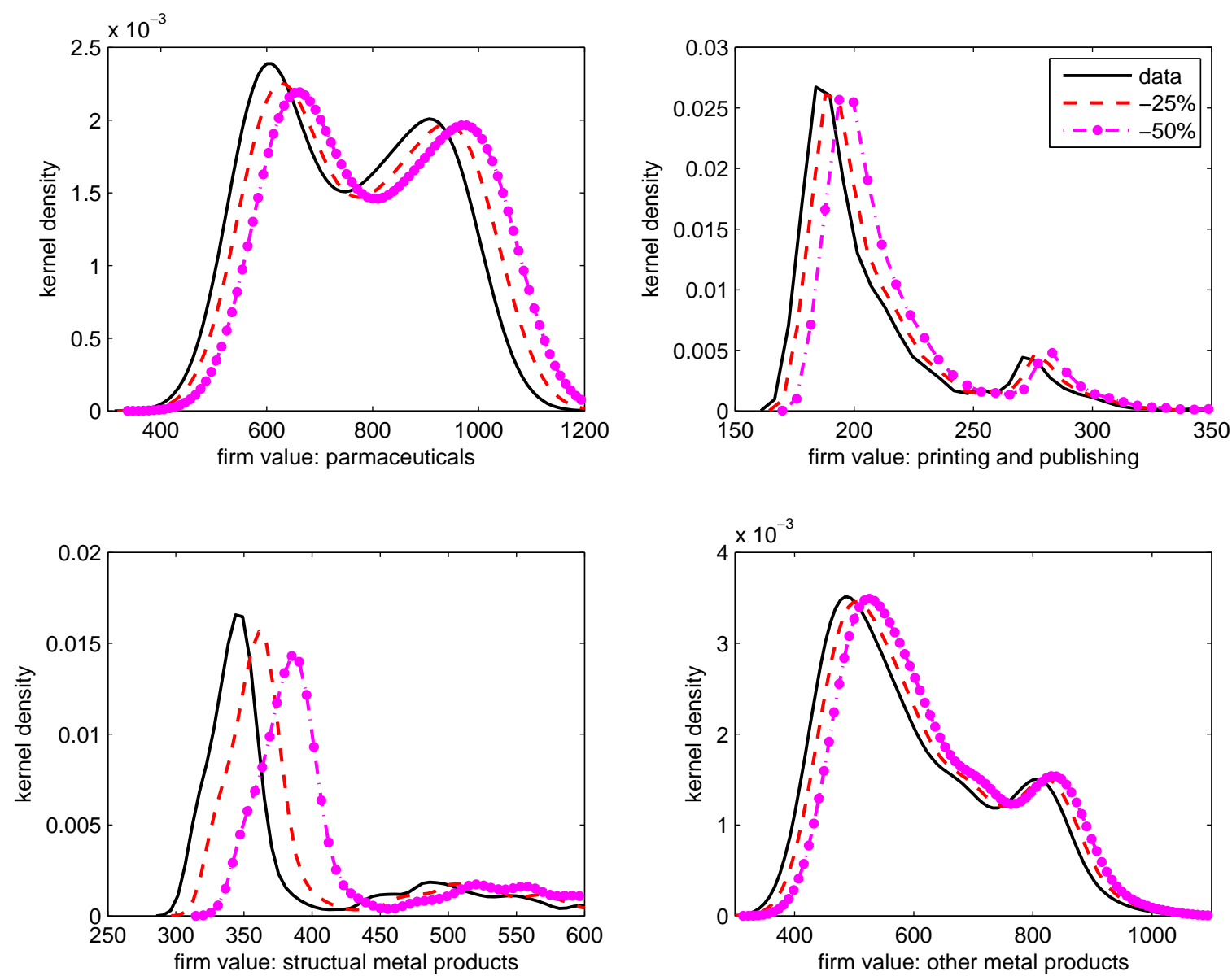